\title{
Electron Paramagnetic Resonance, and Thermoluminiscence Mechanism In Radiation Shielding Cr203 - Ba(La)2SiO6 Glasses
}

RK GUNTU ( $\nabla$ drgrk1985@gmail.com )

SNIST: Sreenidhi Institute of Science and Technology https://orcid.org/0000-0002-9842-4076

\section{Research Article}

Keywords: $\mathrm{Cr} 2 \mathrm{O} 3-\mathrm{Ba}(\mathrm{La}) 2 \mathrm{SiO} 6$ glasses, thermoluminiscence properties, electron paramagnetic resonance, radiation shielding

Posted Date: November 9th, 2021

DOI: https://doi.org/10.21203/rs.3.rs-809608/v1

License: (9) This work is licensed under a Creative Commons Attribution 4.0 International License.

Read Full License 


\title{
Electron paramagnetic resonance, and thermoluminiscence mechanism in radiation
}

\section{shielding $\mathrm{Cr}_{2} \mathrm{O}_{3}-\mathrm{Ba}(\mathrm{La})_{2} \mathrm{SiO}_{6}$ glasses}

\author{
Ravi Kumar Guntu ${ }^{1, *}$
}

*Glass Ceramic Research Laboratory, Department of Physics, Sreenidhi Institute of Science and Technology JNT University, Hyderabad, - 501 301, Telangana State, India.

\begin{abstract}
The research on $\mathrm{Cr}_{2} \mathrm{O}_{3}$ doped $\mathrm{SiO}_{2}$ glasses is well known for advanced dielectrics. However, there are many other valuable properties associated with $\mathrm{Cr}_{2} \mathrm{O}_{3}$ inclusive various glasses. In this view, the current research aimed to develop the radiation shielding, elastically rich, and the EPR based $\mathrm{Cr}_{2} \mathrm{O}_{3}$ doped $\mathrm{Ba}(\mathrm{La})_{2} \mathrm{SiO}_{6}$ glass resource. Electron paramagnetic resonance, radiation shielding, and elastic studies have been employed to investigate the advanced characteristics. Structural characterization suggests glassy behavior with the $\mathrm{Cr}_{2} \mathrm{O}_{3}$ undoped glass. Whereas the other involved with $\mathrm{Cr}_{2} \mathrm{O}_{3}$ mol\% shown with the ceramic behavior. The glass transition phenomena and forming abilities are studied with the help of differential thermal analysis techniques. Elastic studies have been done with the limit on the glasses, which suggests the glasses are flexible for elastic use. The electron paramagnetic resonance reports suggest high order of dipole-dipole superexchange interaction and rhombohedral distortion within the glasses. Furthermore, we have tested the glasses for radiation shielding properties. The values of mass attenuation coefficient, radiation protection efficiency, mean free path, and energy absorption build-up factor of the glasses are measured and compared with values obtained with the help of standard photon shielding and dosimetry software. The studies indicate that the glasses developed are capable of radiation shielding. Upon $50 \mathrm{kGy}, \gamma$ - irradiation, the thermoluminescence properties of the glasses are reported. The results found to be interesting, and reveal the resource developed are thermoluminescent at low activation energies. Furthermore, we have tested, the glasses for radiation shielding properties. Moreover, to introduce the detailed correlation between electron paramagnetic resonance, and thermoluminescence phenomenon, we have annealed the glasses under 0 to $300{ }^{\circ} \mathrm{C}$ temperature and upon the 0 to $50 \mathrm{kGy}, \gamma$ - irradiation dose level. The electron paramagnetic resonance and thermoluminescence properties obtained for the glasses are highly correlative.
\end{abstract}

\section{Keywords}


$\mathrm{Cr}_{2} \mathrm{O}_{3}-\mathrm{Ba}(\mathrm{La})_{2} \mathrm{SiO}_{6}$ glasses; thermoluminiscence properties; electron paramagnetic resonance; radiation shielding;

e-mail: $\underline{\operatorname{drgrk} 1985 @ g m a i l . c o m}$

\section{Introduction}

Usually, the $\mathrm{SiO}_{2}$ glass substances are translucent, hard, non-corrosive, and thermally stable. Their anticipated structural and dielectric characteristics, such as high dielectric constant, low A.E., and values of density of states, will be used for various dielectric applications. There has been significant investigation on silicate glass substances due to their abnormal dielectric determinations considering few decades to recent years $[1,2]$. The $\mathrm{La}_{2} \mathrm{O}_{3}$ is not a pure glass former, but the joining of $\mathrm{La}_{2} \mathrm{O}_{3}$ to the silicate glass substances promotes their elastic characteristics, thermal resistance, non-corrosion features. The joining of $\mathrm{La}_{2} \mathrm{O}_{3}$ to the $\mathrm{SiO}_{2}$ glasses enhance sharp melting point and grainy hardness. Generally, $\mathrm{La}_{2} \mathrm{O}_{3}$ doped silicate glasses are employed as a dosimeter for radiation healing and protection utilization due to their high radiation shielding ability [3, 4]. Incorporating alkali oxides such as $\mathrm{Li}_{2} \mathrm{O}, \mathrm{BaO}, \mathrm{KF}$, and $\mathrm{CaF}_{2}$ into the $\mathrm{La}_{2} \mathrm{SiO}_{5}$ glasses improves third-order non-linearity and electro-optical Kerr - like effect. The addition of $\mathrm{BaO}$ to the $\mathrm{La}_{2} \mathrm{SiO}_{5}$ glasses acts as a refining agent and enhances the polymerization phenomenon $[5,6]$. Amongst the whole transition metal oxides, the nucleation agent $\mathrm{Cr}_{2} \mathrm{O}_{3}$ has been adopted to improve the features of $\mathrm{Ba}(\mathrm{La})_{2} \mathrm{SiO}_{6}$ glass substances considering the collaboration inside the glass interface, and the $\mathrm{Cr}^{3+}$ ions provide fast electron-phonon interaction and promote additional diffusion of thermal radiation [7, 8]. Usually, $\mathrm{Cr}^{3+}$ ions substantially affect the electron paramagnetic resonance, radiation shielding, and dielectric properties of glass materials. Silicate substances, including combined valence states of $\mathrm{Cr}^{3+}$ ions, are of modern importance as a cathode resource in rechargeable batteries as of their unusual energy density and dielectric capacitance $[9,10]$. The octahedral coordinated $\mathrm{Cr}^{3+}$ ions influence polymeric anions within the glassy network, stimulating various other prospects such as chemical durability and volatile nature. The $\mathrm{Cr}_{2} \mathrm{O}_{3}$ uses different materials for paramagnetic studies to survey the magnetic results employing electron spin resonance. The thought, $\mathrm{Cr}_{2} \mathrm{O}_{3}$ doped $\mathrm{Ba}(\mathrm{La})_{2} \mathrm{SiO}_{6}$ glasses will be the most advantageous, academic, and technological subject of research $[11,12]$. Subsequently, in the existing work, $\mathrm{Cr}_{2} \mathrm{O}_{3}$ doped $\mathrm{Ba}(\mathrm{La})_{2} \mathrm{SiO}_{6}$ glass substances are developed and typically study for its suitability towards numerous electron paramagnetic, radiation shielding, and dielectric use. 
Impending credentials such as high density, elastic, thermoluminescent, and radiation shielding etc., are probable over the development of competent solid-state glass substances has fascinated noble recognition.

\section{Methodology}

The compounds of (25-x) mol \% BaO, (x) mol\% $\mathrm{Cr}_{2} \mathrm{O}_{3}, 15$ mol\% $\mathrm{La}_{2} \mathrm{O}_{3}$ and $60 \mathrm{~mol} \% \mathrm{SiO}_{2}$ uses for sample development; where, $\mathrm{x}$ varies with a step size $0.2 \mathrm{~mol} \%$ from 0 to $1.0 \mathrm{~mol} \%$. The melt quenching procedure was to produce the present series of samples. The detailed chemical composition of the present series of glass tests are as follows; $\mathbf{C r - 0 . 0}\left(25.0 \mathrm{BaO}+15 \mathrm{La}_{2} \mathrm{O}_{3}+60 \mathrm{SiO}_{2}+0.0 \mathrm{Cr}_{2} \mathrm{O}_{3}\right), \mathbf{C r}-\mathbf{0 . 2}\left(24.8 \mathrm{BaO}+15 \mathrm{La}_{2} \mathrm{O}_{3}+60\right.$ $\left.\mathrm{SiO}_{2}+0.2 \mathrm{Cr}_{2} \mathrm{O}_{3}\right), \mathbf{C r}-\mathbf{0 . 4}\left(24.6 \mathrm{BaO}+15 \mathrm{La}_{2} \mathrm{O}_{3}+60 \mathrm{SiO}_{2}+0.4 \mathrm{Cr}_{2} \mathrm{O}_{3}\right), \mathbf{C r}-\mathbf{0 . 6}\left(24.4 \mathrm{BaO}+15 \mathrm{La}_{2} \mathrm{O}_{3}+60\right.$ $\left.\mathrm{SiO}_{2}+0.6 \mathrm{Cr}_{2} \mathrm{O}_{3}\right), \mathbf{C r}-\mathbf{0 . 8}\left(24.2 \mathrm{BaO}+15 \mathrm{La}_{2} \mathrm{O}_{3}+60 \mathrm{SiO}_{2}+0.8 \mathrm{Cr}_{2} \mathrm{O}_{3}\right)$, and Cr-1.0 $\left(24.0 \mathrm{BaO}+15 \mathrm{La}_{2} \mathrm{O}_{3}\right.$ + $\left.60 \mathrm{SiO}_{2}+1.0 \mathrm{Cr}_{2} \mathrm{O}_{3}\right)$. The Chemicals, $\mathrm{SiO}_{2}, \mathrm{La}_{2} \mathrm{O}_{3}, \mathrm{BaO}$, and $\mathrm{Cr}_{2} \mathrm{O}_{3}$ (Sigma Aldrich, AR grade $99 \%$ pure) have been chosen in powder form. All the essences in proper mol\% are well mixed in an agate mortar, and programmed furnace and platinum crucibles are employed to melt the mixed powder to form essential glass melt. The melting took place around at $1440{ }^{\circ} \mathrm{C}$, observed, and quenched in the brass holder; further, it has been annealed around $490{ }^{\circ} \mathrm{C}$ as a glass. The dimensionally designed glass samples are used for various characterization. Mass of the glasses recorded with the help of Scale Tech digital weighing balance with a precision of $10^{-4} \mathrm{gm} / \mathrm{cm}^{3}$. Archimedes' principle was used to calculate density values employing known weights of the glasses. The diffraction patterns of glasses are recorded with the help of a Shimadzu X-Ray (XRD-7000) diffracto-meter with a precision of 0.1 degrees. Chemical analysis was examined with the help of the Hitachi S 3700N instrument. The thermal analyser Hitachi DTG-60 H is used to record the DTA thermograms of glasses with a precision of $\pm 1^{\circ} \mathrm{C}$. Ultrasonic velocities, which will be helpful to evaluate the elastic measurements of the glasses, are registered with the help of a WT-311D flaw detector with a precision of $\pm 10 \mathrm{~m} / \mathrm{s}$. Varian E11Z X-Band spectrometer was used to record the EPR spectra of the glasses. The cobalt radioisotopes irradiate the glasses using the GC-5000 irradiation chamber with 0 - $40 \mathrm{kGy}$ dose and a $03 \mathrm{kGy} / \mathrm{h}$ rate. Fricke ASTM E 1026 Standard dosimetry method was used to understand the variation of absorbed doses within the irradiation chamber. The UV-Vis Spectrometric technique was used to record an absorbance value. And the photon-shielding and dosimetry $(\sim 0.015$ to $15 \mathrm{MeV})$ software is used to obtain the theoretical radiation shielding characteristics. The MAT Lab 2.3, Chem Draw Ultra 12.0, and Mac Office 2013 plus software used to analyse the results. 


\section{Results and Discussion}

\subsection{Structure}

Fig.1(a). illustrates, the X-Ray diffraction pattern of the $\mathrm{Cr}_{2} \mathrm{O}_{3}$ free $\mathrm{Ba}(\mathrm{La})_{2} \mathrm{SiO}_{6}$ sample suggests glassy behavior, whereas Fig.1(b). reports the X-Ray diffraction pattern of the other samples expressing ceramic behavior. The peak intensities in X-ray diffraction pattern of the crystalline phase such as $1 . \mathrm{LaCrO}_{3}$, 2. $\mathrm{Ba}_{4} \mathrm{SiO}_{6}, 3 . \mathrm{BaSi}_{2} \mathrm{O}_{6}, 4 . \mathrm{CrSiO}_{4}, 5 . \mathrm{La}_{2} \mathrm{Ba}_{3} \mathrm{O}_{8}, 6 . \mathrm{CrSiO}_{3}, 7 . \mathrm{BaSiO}_{3}, 8 . \mathrm{CrBa}_{2} \mathrm{O}_{4}$ and $9 . \mathrm{Ba}_{3} \mathrm{SiO}_{7}$ were found to be increasing with increased $\mathrm{Cr}_{2} \mathrm{O}_{3}$ mol\%. Parallel to this, the width of the peaks becoming sharper with increased $\mathrm{Cr}_{2} \mathrm{O}_{3} \mathrm{~mol} \%$. This suggests de-clustering in the glass network and crystallinity with increased $\mathrm{Cr}_{2} \mathrm{O}_{3}$ mol\% $[13,14]$. Fig.2 reports the chemical analysis of one BaLaSiCr-1.0 glass, which signifies $\mathrm{Cr}, \mathrm{Si}, \mathrm{O}, \mathrm{Ba}$, and $\mathrm{La}$ chemicals in weight \%. The physical properties of the $\mathrm{Cr}_{2} \mathrm{O}_{3}-\mathrm{Ba}(\mathrm{La})_{2} \mathrm{SiO}_{6}$ glasses are studied. The values of the glasses' molecular weight and glass density are found to be increased with $\mathrm{Cr}_{2} \mathrm{O}_{3}$ weight $\%$. In comparison, the molar volume of glasses decreased with increased $\mathrm{Cr}_{2} \mathrm{O}_{3}$ weight $\%$. Similarly, the refractive index and molar refraction of the glasses increased with increased $\mathrm{Cr}_{2} \mathrm{O}_{3}$ weight $\%$. The quantities optical basicity and oxygen packing density were found to be improved with increased $\mathrm{Cr}_{2} \mathrm{O}_{3}$ weight $\%[15,16]$. Fig.3 reports the DTA thermograms of the $\mathrm{Cr}_{2} \mathrm{O}_{3}-\mathrm{Ba}(\mathrm{La})_{2} \mathrm{SiO}_{6}$ glasses. From which the glass transition $\left(\mathrm{T}_{\mathrm{g}}\right)$ and crystallization $\left(\mathrm{T}_{\mathrm{c}}\right)$ temperatures are reported. The forming abilities of glasses are also computed. Results suggest that the glass with $1.0 \mathrm{Cr}_{2} \mathrm{O}_{3}$ mol\% was the lowest informing abilities, which suggests the depolymerization in glassy behavior and upsurges towards crystallinity behavior $[17,18]$. The high orders of intermolecular force between the $\mathrm{Cr}^{3+}$ ions to the $\mathrm{Ba}^{2+}, \mathrm{Si}^{4+}$, and $\mathrm{La}^{3+}$ ions lead to the order of forming abilities of the glasses. Changes in enthalpy values within the glass network result from variation in both endothermic and exothermic peak intensities. $\mathrm{SiO}_{2}$ is a glass former, and its tetrahedrons have a dissimilar structure interlocked from side to side their corner-sharing. The addition of $\mathrm{La}_{2} \mathrm{O}_{3}$ to the $\mathrm{SiO}_{2}$ glass former forms $\mathrm{Si}$-OLa linkages in which $\mathrm{La}^{3+}$ ions replace $\mathrm{Si}^{4+}$ ions lead to the liberation of free oxygens within the network. The addition of $\mathrm{BaO}$ to the $\mathrm{La}_{2} \mathrm{SiO}_{5}$ glasses produces $\mathrm{Si}-\mathrm{O}-\mathrm{Ba}$ (or) $\mathrm{La}-\mathrm{O}-\mathrm{Ba}$ linkages, influences all the $\mathrm{Si}^{4+}$ and $\mathrm{La}^{3+}$ ions, and improves non-bridging oxygen's. At last, the involvement of $\mathrm{Cr}_{2} \mathrm{O}_{3}$ improves strong crystallinity by forming $(\mathrm{Si} / \mathrm{La} / \mathrm{Ba})-\mathrm{O}-\mathrm{Cr}$ linkages within the glass network.

\subsection{Elastic properties}

Elastic behavior of the $\mathrm{Cr}_{2} \mathrm{O}_{3}-\mathrm{Ba}(\mathrm{La})_{2} \mathrm{SiO}_{6}$ glasses are reported. The elastic (bulk, shear, and young) 
modulus, poison ratio, and microhardness of glasses are tested and evaluated. With the increase of $\mathrm{Cr}_{2} \mathrm{O}_{3}$ weight $\%$ from 0 to $1 \mathrm{~mol} \%$, the density, and elastic (bulk, shear, and young) modulus of the glasses are found to be increased. In comparison, the value of the poison ratio of glasses decreased with increased $\mathrm{Cr}_{2} \mathrm{O}_{3}$ weight $\%$. Similarly, the microhardness of glasses increased with increased $\mathrm{Cr}_{2} \mathrm{O}_{3}$ weight $\%$. They have computed all the elastic standards of glasses reported in table. The vulnerabilities in the dimensions of the interstitial gaps and variation in the co-ordination of the $\mathrm{Ba}^{2+}, \mathrm{Cr}^{3+}, \mathrm{Si}^{4+}$, and $\mathrm{La}^{3+}$ ions are the reason for the interpretation of density, molar volume, refractive index, and optical basicity. For most of the parts, the glass materials are of supreme elastic relevance under any glass formation. Generally, the various elastic modulus of glass materials is interdependent thought of holding intermolecular dominance. In some glass (or) glassceramic materials, elastic modulus improves through a conventional magnitude of the atomic density. Replacement of the $\mathrm{La}^{3+}$ ions by divalent $\mathrm{Cr}^{3+}$ ions within the glass leads to higher orders of the elastic module. Microhardness of glasses prescribe additional information and supports for a covalently interlinked structure. An increase in atomic density and variations in interstitial defects could be another reason for elastic characteristics $[19,20]$.

\subsection{Electron paramagnetic resonance}

Fig.4 reports the E.P.R. spectrum of $\mathrm{Cr}_{2} \mathrm{O}_{3}-\mathrm{Ba}(\mathrm{La})_{2} \mathrm{SiO}_{6}$ glasses. The spectra reveal the characteristic hyperfine structure of the $\mathrm{Cr}^{3+}$ ions. The spectra also reveal two resonance signals at low and high field regions. Similarly, intensities observed around at the center of the spectra with a 'g' values of $1.97,2.38,4.25$, and 5.23 are due to rhombic distortion. The 'g' values of glasses were increased with $\mathrm{Cr}_{2} \mathrm{O}_{3}$ concentration, suggesting the increased nature of ionic bonding. At first, in the $\mathrm{Cr}_{2} \mathrm{O}_{3}-\mathrm{Ba}(\mathrm{La})_{2} \mathrm{SiO}_{6}$ glasses, the $\mathrm{Cr}^{3+}$ ions predominately occupy $\left(\mathrm{CrO}_{4}\right)$ sites tetrahedrally, and it is changing with the increase of the $\mathrm{Cr}_{2} \mathrm{O}_{3}$ weight\% from 0 to $1 \mathrm{~mol} \%$ with a step size of $0.2 \mathrm{~mol} \%$ they are occupying octahedral $\left(\mathrm{CrO}_{6}\right)$ sites. The intensities of resonance signal are increased with an increase of the $\mathrm{Cr}_{2} \mathrm{O}_{3}$ weight $\%$ from 0 to $1 \mathrm{~mol} \%$. The super-exchange interaction between dipoles raised due to $\mathrm{Cr}^{3+}$ ions within the glasses might be the reason for such a phenomenon. The observed increase in the values of g-factor with an increase of the $\mathrm{Cr}_{2} \mathrm{O}_{3}$ weight $\%$ from 0 to $1 \mathrm{~mol} \%$ is due to non-zero orbital angular momentum. The hyperfine splitting factor $(\mathrm{g})$ gives precise information about the predominance of the $\mathrm{Cr}^{3+}$ ions within the glass network. The E.P.R. spectra of the $\mathrm{Cr}_{2} \mathrm{O}_{3}$ - $\mathrm{Ba}(\mathrm{La})_{2} \mathrm{SiO}_{6}$ glasses reveal the ionic environment around the $\mathrm{Cr}^{3+}$ ions. And which is also increasing with 
increasing concentration of $\mathrm{Cr}_{2} \mathrm{O}_{3}$ within the glassy network. The product of the peak height and square of the bandwidth reveal the intensity of the E.P.R. signal. And it is increased with $\mathrm{Cr}_{2} \mathrm{O}_{3}$ weight $\%$ from 0 to 1 mol $\%$. The Chromium ion has three unpaired electrons with $\mathrm{S}=3 / 2, \mathrm{~L}=3$, and $\mathrm{J}=3 / 2$. Hence these ions' orbital degeneracy is seven with the ground state of ${ }^{4} \mathrm{~F}_{3 / 2}$. The system's total spin-Hamiltonian [21-24] is given by $H=\beta$ H.g.S + I.A.S + S.D.S $\beta H . g . S-$ spin magnetic interaction.

I.A.S. - electron and nuclear magnetic moment hyperfine interaction.

S.D.S. - electron spin and crystal field interaction.

The high values of $g$ factor $(\sim 5.23)$ are responsible for the rhombic symmetry with in the glasses. In contrast, low $\mathrm{g}$ values at $\mathrm{g}(\sim 1.97)$ arise from the $\mathrm{Cr}^{3+}$ centers in the distorted cubic sites. Due to the simultaneous interaction of $\mathrm{Cr}^{3+}$ ion pairs, and the isolated $\mathrm{Cr}^{3+}$ ion centers, additional $\mathrm{g}$ values at $\sim 2.38$. The $\mathrm{Fe}^{3+}$ impurity ions cause weak signal with g value at $\sim 4.25$.

\subsection{Radiation shielding properties}

The photon-shielding and dosimetry ( 0.015 to $15 \mathrm{MeV}$, Cs-137) software is used to obtain the radiation shielding characteristics of the $\mathrm{Cr}_{2} \mathrm{O}_{3}-\mathrm{Ba}(\mathrm{La})_{2} \mathrm{SiO}_{6}$ glasses. The shielding characteristics such as MAC $(\mu / \rho)$, EAN (Zeff), HVL, MFP, RPE, and EBF are evaluated theoretically to explore the proficiency of the $\mathrm{Cr}_{2} \mathrm{O}_{3}$ $\mathrm{Ba}(\mathrm{La})_{2} \mathrm{SiO}_{6}$ glasses. The subsequent equation can be employed to calculate the experimental LAC $(\mu$ - linear attenuation coefficient) values $[25,26]$.

$\mathrm{I}=\mathrm{I}_{0} \mathrm{e}^{\mu \mathrm{t}}$

Where, $\mathrm{t}$ - thickness, $\mathrm{I}_{0}$ - incident photons, and I - transmitted photons

Mass attenuation co-efficient $=\mu / \rho$

$\mu-$ LAC (linear attenuation coefficient), and $\rho$ - density

The radiation shielding aspects are intensely interlinked with a density of glasses. The photon absorption and scattering probability can be applied to determine with the help of the MAC $\left(\mathrm{cm}^{2} / \mathrm{g}\right)=\sum_{i} w_{i}\left(\frac{\mu}{\rho}\right)_{i}$.

In this expression, $\left(\frac{\mu}{\rho}\right)_{i}$ represents MAC of $\mathrm{i}^{\text {th }}$ element of the glass matrix.

The variation in the MAC $\left(\mathrm{cm}^{2} / \mathrm{g}\right)$ against photon energy $(\sim 0.015$ to $15 \mathrm{MeV})$ with an increase in $\mathrm{the}_{2} \mathrm{Cr}_{2} \mathrm{O}_{3}$ concentration is presented in Fig.5(a) - Inset (b). The results reveal, the peak at $0.0659 \mathrm{MeV}$ in the MAC traces 
represents the $\mathrm{K}$-absorption edge and which was due to the presence of $\mathrm{Cr}^{3+}$ ions. The results also suggest that the variations in the value of the MAC $\left(\mathrm{cm}^{2} / \mathrm{g}\right)$ with the $\mathrm{Cr}_{2} \mathrm{O}_{3}$ increased weight $\%$ and photon energy. The value of the MAC is evaluated to be lowest $\left(16.119 \mathrm{~cm}^{2} / \mathrm{g}\right)$ for the BLSCr- 0.2 glass at $511 \mathrm{eV}$ photon energy and highest $\left(19.121 \mathrm{~cm}^{2} / \mathrm{g}\right)$ for the BLSCr-1.0 glass at $511 \mathrm{eV}$ photon energy. The gradual increase in $\mathrm{Cr}^{3+}$ ions replaces 2-fold $\mathrm{La}^{3+}$ ions within the glassy network, increasing the physical characteristics, which further lead to the rise in MAC values. The photoelectric phenomenon and its predominance are the reason for increased MAC values, increasing $\mathrm{Cr}_{2} \mathrm{O}_{3}$ weight \% in the low phonon energy $(0.015 \mathrm{MeV}-0.662 \mathrm{MeV})$ range. The magnitude of the photoelectric phenomenon is considered relative to the EAN ( $\left.Z_{\text {eff }}\right)$ and phonon energy (E), which influence the order of decrease in the MAC values $\left(16.812 \mathrm{~cm}^{2} / \mathrm{g}\right.$ at $511 \mathrm{eV}$ to $7.483 \mathrm{~cm}^{2} / \mathrm{g}$ at $215 \mathrm{eV}$ ) of BLSCr-1.0 glass. The results suggested a predominance of the photoelectric phenomenon at a low energy range and observed with other glasses within the series. The order of the MAC values of glasses within the high photon energy range is almost close to each other. Due to the high order of Compton scattering phenomenon, it suggests the scattering probability of glasses directly related to EAN ( $\left.Z_{\mathrm{eff}}\right)$ and pair production. The quantity the EAN ( $\left.Z_{\text {eff }}\right)$ also characterizes the shielding phenomenon of glasses. The EAN ( $\left.Z_{\text {eff }}\right)$ evaluations are obtained by using the photon-shielding and dosimetry program. The next equation can be employed to determine radiation protection efficiency $[27,28]$

$\mathrm{RPE}=\left[1-\left(\mathrm{I} / \mathrm{I}_{0}\right)\right] \times 100 \%$.

The EAN ( $\left.\mathrm{Z}_{\text {eff }}\right)$ values reported in Fig.5(a) - Inset (a) observed to be high in the low in photo electric region (photon energy region). After that continuous decrease in the EAN ( $\left.Z_{\text {eff }}\right)$ values within the Compton scattering region, and for some energy range, the EAN ( $Z_{\text {eff }}$ ) values are also found to be constant as well. There is some increase in the EAN ( $\left.\mathrm{Z}_{\mathrm{eff}}\right)$ values beyond the $300 \mathrm{keV}$ of gamma energy, which suggests high orders of the photo-electric phenomenon. Similar reports are observed with other glasses as well. The reported EAN (Zeff) values for the BLSCr-0.0, BLSCr-0.2, BLSCr-0.4, BLSCr-0.6, and BLSCr-1.0 glasses varied in the range $52.31-20.79,52.43-21.07,52.79-22.16,52.53-22.43$, and $52.81-23.84$ respectively. The significant increase in the EAN ( $\mathrm{Z}_{\text {eff }}$ ) values with the addition of the $\mathrm{Cr}_{2} \mathrm{O}_{3}$ weight $\%$ is attributed to the $\mathrm{La}_{2} \mathrm{O}_{3}$ molecule replacement with the $\mathrm{Cr}_{2} \mathrm{O}_{3}$ molecule. Generally, LAC $=$ MAC $\times$ density of the glass. The HVL $(0.693 / \mu)$ and MFP $(1 / \mu)$ of the glass can be judged by using MAC $\left(\mathrm{cm}^{2} / \mathrm{g}\right)$ values. Generally, the glasses with low HVL values are used for radiation shielding. Fig.5(b) - Inset (a) describes the photon energy $(0.015-15 \mathrm{MeV})$ 
against variation in the HVL parameter of glasses. Upon low photon energy range, the HVL trace's observed to be constant, and for all other content of temperature, there is a drastic increase in HVL values. The direct relation between the HVL and photon energy will be the reason for all the results. Fig.5(b) - Inset (a) suggests the values of $\mathrm{HVL}$ decrease with the increase of $\mathrm{Cr}_{2} \mathrm{O}_{3}$ weight\% from 0 to 1 mol \%, justifies more $\mathrm{Cr}_{2} \mathrm{O}_{3}$ weight $\%$ in glasses are preferable for radiation shielding. Fig.5(a) - Inset (c) summarizes the MFP values against with photon energy $(0.015-15 \mathrm{MeV})$ of glasses. The results suggest the values of the MFP follow a similar trend as HVL values against the photon energy, which are due to linear and direct MAC dependence on photon energy in various regions. The glass, BLSCr-1.0 exhibiting the maximum MFP value, whereas the BLSCr-0.2 glass was found to be with the lowest MFP value. The entire phenomenon was due to the values of density increasing with $\mathrm{Cr}_{2} \mathrm{O}_{3}$ weight $\%$ from 0 to $1 \mathrm{~mol} \%$ and increased MAC values. From this, it can be presupposed that less distance is sufficient for photons to undergo uninterrupted impacts in BLSCr-1.0 glass shows its more remarkable radiation shielding ability. The parameters, penetration depth, radiation protection efficiency, and energy build-up factor increase with an increase in photon energy within the glasses. Naturally, to attenuate high-energy photons, more thickness of the glass has to be prepared. The radiation shielding studies of the glasses suggest the radiation shielding phenomenon purely a function of the $\mathrm{Cr}_{2} \mathrm{O}_{3}$ concentration. The glass with a high BLSCr-1.0 concentration exhibiting in the best shielding implementation, preferably in a low photon energy range. The values of the MAC, HVL, MFP, RPE, and EBF suggest more glassy thickness is required to attenuate high-energy radiation $[29,30]$.

\subsection{Thermoluminiscence}

Fig.6 reports the thermoluminescence of the $\mathrm{Cr}_{2} \mathrm{O}_{3}-\mathrm{Ba}(\mathrm{La})_{2} \mathrm{SiO}_{6}$ glasses under $50 \mathrm{kGy}$ constant irradiation dose, recorded within the temperature range of 27 to $300{ }^{\circ} \mathrm{C}$. The glass test arranged with $\mathrm{x}=1.0 \mathrm{~mol} \%$ showing the maximum thermoluminescence effect. The thermoluminescence results are found to be with two peak intensities in which one is around at $110^{\circ} \mathrm{C}$, and the other is around at $150-165{ }^{\circ} \mathrm{C}$. The observed lowtemperature peak with less intensity fades within 10 hours. With the increase of $\mathrm{Cr}_{2} \mathrm{O}_{3}$ weight\% in host glass from 0 to $1 \mathrm{~mol} \%$ with a $0.2 \mathrm{~mol} \%$ of step size, there are many thermoluminescence peak intensities and shifts in glow peak temperature. The glass BLSCr-1.0 is observed to be optimum in the thermoluminescence glow peak intensity. The following equations are used to analyse the trap-depth parameters of glasses [31, 32]. 
$E_{\theta}=C_{\theta}\left(\frac{\mathrm{KT}_{m}^{2}}{\tau}\right) 2 \mathrm{KT}-\mathrm{b}_{\theta}\left(2 \mathrm{KT}_{\mathrm{m}}\right) ;$ Where, $\theta=\tau, \delta$, and $\omega$

$\mathrm{S}=\frac{\beta \mathrm{E}}{\mathrm{KT}_{\mathrm{m}}^{2}} \exp \left(\frac{\mathrm{E}}{\mathrm{kT}_{\mathrm{m}}}\right)\left[1+(\mathrm{b}-1) \Delta_{\mathrm{m}}\right]^{-1}$

where,

$\Delta_{\mathrm{m}}=\frac{2 \mathrm{kT}}{\mathrm{E}} ; \tau=\mathrm{T}_{\mathrm{m}}-\mathrm{T}_{1}, \delta=\mathrm{T}_{2}-\mathrm{T}_{\mathrm{m}}$, and $\omega=\mathrm{T}_{2}-\mathrm{T}_{1}$

$T_{m}$ - peak temperature maximum; $T_{1}$ - left side temperature intercept on glow curve at $T_{m} / \sqrt{ } 2$ value;

$T_{2}$ - right side temperature intercept on glow curve at $T_{m} / \sqrt{2}$ value;

$\mu_{\mathrm{s}}$ - symmetry;

$\beta$ - heating rate;

$\mathrm{C}_{\mathrm{t}}, \mathrm{C}_{\delta}$, and $\mathrm{C}_{\mathrm{w}}$ are $[1.51+3(\mathrm{~m}-0.42)],[0.97+7.3(\mathrm{~m}-0.42)], \&[2.52+10.2(\mathrm{~m}-0.42)] ;$

$b_{t}, b_{\delta}$, and $b_{w}$ are $[1.51+3(m-0.42)], 0$, and 0 ;

With the increase of $\mathrm{Cr}_{2} \mathrm{O}_{3}$ weight $\%$ from 0 to $1 \mathrm{~mol} \%$, the thermoluminescence measurements of glasses found to be increased, up to $01 \%$ of $\mathrm{Cr}_{2} \mathrm{O}_{3}$ content found to be best in results. One of the section in Table.1 reports the TL characteristics of the $\mathrm{Cr}_{2} \mathrm{O}_{3}-\mathrm{Ba}(\mathrm{La})_{2} \mathrm{SiO}_{6}$ glasses. With the increase of $\mathrm{Cr}_{2} \mathrm{O}_{3}$ weight $\%$ from 0 to $1 \mathrm{~mol} \%$, the TL measurements of glasses found to be increased, and the glass with $1.0 \%$ of $\mathrm{Cr}_{2} \mathrm{O}_{3}$ content found to be best in results. Thermoluminescence dosimetry is the widely used means of dosimetric measurements, especially for personnel monitoring of radiation workers. The materials used for personnel monitoring should meet several requirements like high sensitivity, low fading, linear response over a wide range of doses, and no energy dependence. A single material may not satisfy all the requirements for personnel dosimetry. The field evolves by developing new materials or improving the characteristics of existing phosphors by using different synthesis techniques or changing the dopants. Most inorganic compounds exhibit thermoluminescence. However, to use a phosphor for dosimetric applications, it should qualify some properties, limiting the choice to only a handful of materials. Some of the most desirable properties that qualify a phosphor for dosimetric applications are a high concentration of electrons and hole traps and high efficiency in the recombination process resulting in intense light emission upon heating (high sensitivity). This paper section presents important dosimetric characteristics like TL glow curve, TL emission wavelength, and gamma dose-response of the glasses. The variation in the glow curves of glasses are studied with increased $\mathrm{Cr}_{2} \mathrm{O}_{3} \%$, and the optimum concentration was determined for each of the glasses. Also, the other dosimetric 
parameters like reusability, storage stability, light sensitivity, reproducibility in synthesis, etc., are studied. Lithium tetraborate is one of the TL phosphors studied for a long time since its first introduction due to its tissue equivalence. But the $\mathrm{Cr}_{2} \mathrm{O}_{3}-\mathrm{Ba}(\mathrm{La})_{2} \mathrm{SiO}_{6}$ glasses synthesized by using the melt quenching technique have a high-temperature glow peak and hence benefit minor fading. Hence a detailed investigation has been carried out on this material concerning increasing the TL intensity and dose-response. The increase of $\mathrm{Cr}_{2} \mathrm{O}_{3}$ weight $\%$ from 0 to $1 \mathrm{~mol} \%$ improves the structural defect centers within the glasses [33, 34]. Once glasses are subjected to the thermal energy, the electrons are liberated from $\mathrm{La}^{3+}, \mathrm{Si}^{4+}, \mathrm{Cr}^{3+}$, and $\mathrm{Ba}^{2+}$ ions. Later, recombined these electron centers with hole trap centers cause thermoluminescence. Glass BLSCr-1.0 was observed to be highest among all the trap depth findings of glasses. Predominantly, interstitial positions of both the valence states corresponding to the $\mathrm{Cr}^{3+}$ ions cause a higher imperative nephelauxetic effect within the $3 \mathrm{~d}$ levels of $\mathrm{Cr}^{3+}$ ions, contribute to enhanced TL emission. The Octahedral $\mathrm{CrO}_{6}$ units act as modifiers and induce binding defects. And the increase of $\mathrm{La}-\mathrm{O}-\mathrm{Si}, \mathrm{Ba}-\mathrm{O}-\mathrm{Si}$, and $\mathrm{Cr}-\mathrm{O}-\mathrm{Si}$ linkages could enhance TL emission. The increased no of octahedral $\mathrm{CrO}_{6}$ units induces interstitial and volume defects, which cause higher order of disorder within the glasses. TL output intensities are dependent on $\mathrm{La}^{3+}, \mathrm{Si}^{4+}, \mathrm{Cr}^{3+}$, and $\mathrm{Ba}^{2+}$ ions site symmetry, order of $\mathrm{Ba}-\mathrm{O}, \mathrm{La}-\mathrm{O}$, and $\mathrm{Cr}-\mathrm{O}$ bond linkages, and balanced interatomic force within the glasses. The information concerning to the reported various characterization such as physical, elastic, thermal, radiation shielding, paramagnetic and thermo-luminance of the glasses represent in table.

\section{Correlation - Electron paramagnetic resonance, and thermoluminiscence}

In this section, the correlation between TL and EPR signals is explained in detail. The phenomenon of irradiated induced defects in the materials is the necessary identification in TL-based many applications. The complete information concerning the charge traps in the TL mechanism cannot be acquired by carrying TL measurements alone. In this view, there is an EPR technique, which can be helpful to find a lot more information about paramagnetic species such as charge traps (trapped hole or an electron). In general, EPR provides a non-destructive way of obtaining the results about charge traps in TL materials. Generally, TL analysis of glasses provides information about the charge trap centers but the nature of traps. But the information concerning the nature of the hole and electron traps cannot be determined by using the TL technique. In comparison, the EPR technique, which describes the splitting of energy levels under the applied magnetic field, will be used to evaluate the number of defects centers up to the $10^{-9}$ molar concentrations, 
which is not in the order of $10^{-15}$ molar concentrations, where the range, at which TL analysis will typically be taking place. The following assumptions have been introduced to correlate the TL and EPR phenomena $[35,36]$.

(a) TL : all the traps centers need not be paramagnetic radicals

(b) EPR : all the paramagnetic radicals of irradiated glass need not be traps centers

For accurate correlation, one should study the isothermal decay of the TL analysis, which includes annealing treatment at all the prominent temperatures that could be investigated. Parallelly, the EPR has been done within a range of radiation doses, which has to be close to the TL saturation dose. In comparison, the TL analysis has done within a radiation dose, which has to be lower than the saturation dose. This is obviously due to the EPR-TL correlation provides the information only on trap centers. Similarly, the radiation-induced defects in lanthanum-based silicates will be evaluated by using the EPR technique. The EPR analysis will understand the possible forming defect centers of the glasses with irradiation.

Fig.7 reports the possible defect centers in the barium-based lanthanum silicate glasses with dopants of $\mathrm{Cr}^{3+}$ ions, which is found to be with network formers such as $\mathrm{D}_{1}, \mathrm{D}_{2}$, and $\mathrm{D}_{3}$ (silicate constitutes), those surrounding oxygen atoms in a tetrahedral configuration. In the figure, if $\mathrm{D}_{3}$ is silicate constitute until isolation of charge compensated cation, the observed complex $\mathrm{D}_{3} \mathrm{O}_{4}$ may act as a harmful point defect. Such point defects play a vital role as hole traps. And those are also named SOHC (silicate oxygen hole centers). The NBO's (non-bridging oxygen) at $\mathrm{D}_{1}$ will act as another defect (negatively charged), which can trap a hole by interstitially surrounded cations in the network. The irradiation effect on glasses will induce SEC (silicate electron trap centers) within the network due to differences in electron affinity and similarity in valency of $\mathrm{D}_{2}$ and $\mathrm{D}_{1}$ network formers. In such cases, the electrons within the network will be trapped at the orbital of Si-O bonding. The presence of interstitial ions (charge compensated) nearer to the defect centers will increase defect canters' significance and serve the electron traps themselves. The addition of $\mathrm{Cr}_{2} \mathrm{O}_{3}$ will form oxygen vacancies within the network. Those will further help to increase the formation of electron trap centers within the network. The non-irradiated, irradiated (1 kGy), and annealed glasses at various temperatures are taken for the EPR studies to identify the TL responsible defect centers. The results suggest that the glass with 1.0 mol\% $\mathrm{Cr}_{2} \mathrm{O}_{3}$ concentration was optimal for TL responsible defect centers. Fig.8(a), and (b) reports the EPR analysis of glasses observed under different conditions. One of the EPR traces of the glass with $1.0 \mathrm{~mol} \%$ 
$\mathrm{Cr}_{2} \mathrm{O}_{3}$ concentration is shown in the figure. The results observed (resonance line, at $\mathrm{g} \sim 1.97,2.38,4.25$, and 5.23) from the figure reveal the nature of $\mathrm{Cr}^{3+}$ paramagnetic constitutes within the glasses. $\mathrm{The} \mathrm{Cr}-\mathrm{Cr}$ exchange-coupled dipolar interactions lead to the characteristic unresolved broad line in the EPR spectra of glasses. Due to low $\mathrm{Cr}_{2} \mathrm{O}_{3}$ concentrations within the network, the intensities observed trim in order. Irradiated glasses, free radicals in the electron-free resonance region are found to be at $\mathrm{g} \sim 1.97,2.38,4.25$, and 5.23 region. Generally, the $\mathrm{SiO}_{2}$ glasses exhibit asymmetrical, rocking, and symmetrical structural units. The motif of barium-based lanthanum silicate glasses consists of $\mathrm{Si}-\mathrm{O}$ complex (two silicon atoms + six oxygen atoms), arranged as two identical tetrahedral groups. Four such Si-O complexes are present in one unit cell of the barium-based lanthanum silicate glasses, and the barium ions stabilize the Si-O framework. The TL emission in the barium-based lanthanum silicate glasses is the characteristic phenomenon of the $\mathrm{Cr}^{3+}$ ions. In this view, irradiated the barium-based lanthanum silicate glasses exhibited two paramagnetic radicals as well. A center with a g-value of 5.23 is acknowledged as a 'silicate oxygen hole center' (SOHC), which reveals a hole trapped on an oxygen ion that links two the $\mathrm{SiO}_{4}$ units. The results characterize a hole trapped at the bridging oxygen of the two tetrahedral networks in the Si-O complex. Due to the lack of positive charge at the silicate site and with an Mn substitution, the hole trapped at this center becomes more stable. This trapped hole caused the breakage of the bond between the two tetrahedral networks, and hole centers at broken oxygen bonds are known to exhibit high thermal stabilities. The luminescence (orange-red) band $\mathrm{of}^{3+}$ at the position of tetrahedral $\mathrm{Si}^{4+}$ ion is excited when the hole trapped at the bridging oxygen (SOHC) undergoes recombination with some electron. This is because the electronic clouds of $\mathrm{Cr}^{3+} \mathrm{d}$-electrons overlap with the valence electron clouds of the oxygen ligands, resulting in a decrease in the emission energy. Thus SOHC is identified as a hole trapping center in barium-based lanthanum silicate lattice. The g-value of 5.23 was identified as a center2 due to electrons trapped at oxygen vacancies within the network. The $\mathrm{SiO}_{4}$ structural units will become more stable once the electrons start trapped at the oxygen vacancy surroundings of $\mathrm{SiO}_{4}$ structural units. When $\mathrm{Cr}_{2} \mathrm{O}_{3}$ is doped in the barium-based lanthanum silicates, it is understood that $\mathrm{Cr}^{3+}$ can occupy the $\mathrm{La}^{3+}$ sites and also to the $\mathrm{Si}^{4+}$ tetrahedral sites. The charge compensated oxygen vacancies are created within the lattice based on the dopant $\left(\mathrm{Cr}_{2} \mathrm{O}_{3}\right)$ concentration $[37,38]$.

And the created oxygen vacancies are stable at room temperature and act as electron trap centers within the lattice. After the required irradiation, the holes are trapped with bridging oxygen atoms, whereas the electrons 
are trapped with oxygen vacancies. The EPR studies under the different annealing temperature range from 50 to $300{ }^{\circ} \mathrm{C}$, and with a step size of $50^{\circ} \mathrm{C}$ have done on irradiated barium-based lanthanum silicate glasses are introduced to understand the thermal stability behavior of traps and to make an analogy for TL results. The results reveal the centers observed are stable until $210^{\circ} \mathrm{C}$; after that, a sudden decrease in order of temperature. The TL glow curves are also recorded on all the barium-based lanthanum silicate glasses. The EPR measurements are carried out to measure the thermal decay of the TL in the glass with $1.0 \mathrm{~mol} \%$ of $\mathrm{Cr}_{2} \mathrm{O}_{3}$ concentration. Fig. 9 reports the relative variation of TL and EPR signal of the distinguished radicals of irradiated glass with $1.0 \mathrm{~mol} \%$ of $\mathrm{Cr}_{2} \mathrm{O}_{3}$ concentration at different annealing temperatures around one hour. The observed results from the figure suggest that the order of decrease in the EPR signal relative to the TL signal. The subsequent comparison will be used to calculate the thermal activation energy of the SOHC center within the network, which is the leading cause for these radicals in the TL mechanism $[39,40]$.

$\ln \left[-\ln \left(1-\frac{\Delta \mathrm{I}}{\mathrm{I}}\right)\right]=$ Constant $-\frac{\mathrm{E}_{\mathrm{a}}}{\mathrm{kT}}$

Where, I - Signal intensity of irradiated glass

$\Delta$ - Amount of decrease in the EPR signal

$\mathrm{E}_{\mathrm{a}}$ - thermal activation energy

The thermal destruction SOHC and oxygen valance center activation energies are found to be 1.31 and 1.35 $\mathrm{eV}$. The trap depth $(1.29 \mathrm{eV})$ was also determined by using TL kinetic analysis. All the results were found to be highest for the glass with $1.0 \mathrm{~mol} \%$ of $\mathrm{Cr}_{2} \mathrm{O}_{3}$ concentrations. Based on the above analysis, the following model is proposed for the mechanism of thermoluminescence glass with 0.1 mol\% of $\mathrm{Cr}_{2} \mathrm{O}_{3}$ concentration.

Upon Irradiation

$\left[\mathrm{Ba}(\mathrm{LaSi})_{2}\right] \mathrm{O}_{2}: \mathrm{Cr} \rightarrow=\mathrm{SOHC}, \mathrm{O}_{\mathrm{V}}^{-}$(Oxygen vacancy ceter)

Upon heating

$\mathrm{SOHC} \rightarrow \mathrm{h}$

$\mathrm{O}_{\mathrm{V}}^{-}$(oxygen vacancy) $+\mathrm{h} \rightarrow\left(\mathrm{Cr}^{2+}\right)^{*} \rightarrow \mathrm{Cr}^{3+}+\mathrm{hu}(\mathrm{TL})$

Under the suitable irradiation,

(a) the electrons are trapped at oxygen vacancies

(b) Holes are trapped at $\mathrm{SiO}_{4}$ tetrahedra bridging oxygens 
In this process, the $\mathrm{Si}^{4+}$ ions are replaced with two $\mathrm{Cr}^{3+}$ ions, which leads to weaker $\mathrm{Si}-\mathrm{O}$ linkages within the network. Upon heating, the holes are unconstrained from the SOHC center and recombine with the electrons trapped at oxygen vacancies. The non-radiative energy liberated through recombination is transferred to the nearby $\mathrm{Cr}^{3+}$ ions substituted for $\mathrm{La}^{3+}$ ions. And which also leads to characteristic emission spectra from excited $\mathrm{Cr}^{3+}$ ions with the orange-red region.

\section{Conclusion}

In the synchronous research, we have integrated multifunctional $\mathrm{Cr}_{2} \mathrm{O}_{3}-\mathrm{Ba}(\mathrm{La})_{2} \mathrm{SiO}_{6}$ glasses. Various structural, elastic, photo-electronic, and thermoluminescent techniques are used to characterize the glasses. The thermal stabilities of the glasses are reported from the DTA studies. The studies also reveal the higher order of intermolecular force and covalence between $\mathrm{Cr}^{3+}$ ions to all other $\mathrm{Ba}^{2+}, \mathrm{La}^{3+}$, and $\mathrm{Si}^{4+}$ ions in a glass with $1.0 \mathrm{~mol} \% \mathrm{Cr}_{2} \mathrm{O}_{3}$ concentration. Ultrasonic velocities were recorded to evaluate the elastic characteristics of glasses. Under elastic characterization, considered microhardness $(9.15 \sim \mathrm{GPa})$ range, suggest higher rigidity and elastic strength of glasses. The Radiation shielding studies of glasses suggest the radiation shielding phenomenon purely a function of the $\mathrm{Cr}_{2} \mathrm{O}_{3}$ concentration. The glass with 1.0 mol\% $\mathrm{Cr}_{2} \mathrm{O}_{3}$ concentration exhibiting in best shielding implementation, preferably at a low photon energy range. The values of MAC, HVL, MFP, RPE, and EBF suggest more glassy thickness is required to attenuate high energy radiation. The TL studies of $\mathrm{Cr}_{2} \mathrm{O}_{3}-\mathrm{Ba}(\mathrm{La})_{2} \mathrm{SiO}_{6}$ glasses are reported. The kinetic parameters of BLSCr-1.0 glass was determined, and the trap depth was found to be around $1.992 \mathrm{eV}$. The frequency factor was of the order of $1.66 \times 10^{-53} \mathrm{~S}^{-1}$. And those are found high for the with $1.0 \mathrm{~mol} \% \mathrm{Cr}_{2} \mathrm{O}_{3}$ concentration under thermoluminescence studies are valuable TL assets. The EPR studies of $\mathrm{Cr}_{2} \mathrm{O}_{3}-\mathrm{Ba}(\mathrm{La})_{2} \mathrm{SiO}_{6}$ glasses are reported. The EPR spectra reveal the characteristic sextet hyperfine structure of $\mathrm{Cr}^{3+}$ ions present within the glasses. The high values of $\mathrm{g}$ factor $(\sim 5.23)$ are responsible for the rhombic symmetry with in the glasses. In contrast, low $\mathrm{g}$ values at $\mathrm{g}(\sim 1.97)$ arise from the $\mathrm{Cr}^{3+}$ centers in the distorted cubic sites. Due to the simultaneous interaction of $\mathrm{Cr}^{3+}$ ion pairs, and the isolated $\mathrm{Cr}^{3+}$ ion centers, additional $\mathrm{g}$ values at $\sim 2.38$ with in the network. With the increase of the $\mathrm{Cr}_{2} \mathrm{O}_{3}$ weight $\%$ from 0 to $1 \mathrm{~mol} \%$, the ' $\mathrm{g}$ ' values of glasses were increased, which also suggests the progressive nature of ionic bonding within the network. The observed increase in the importance of g-factor with an increase of the $\mathrm{Cr}_{2} \mathrm{O}_{3}$ weight $\%$ from 0 to $1 \mathrm{~mol} \%$ is due to the non-zero orbital angular momentum of predominant $\mathrm{Cr}^{3+}$ ions. Under irradiation, the defect centers formed 
within the $1.0 \mathrm{~mol} \% \mathrm{Cr}_{2} \mathrm{O}_{3}$ concentration are determined. The thermal decay of the EPR signals is obtained and compared with the thermal decay of TL signals. To introduce the EPR - TL correlation, the necessary TL responsible free radicals, and paramagnetic defect centers are identified. The thermal decay of the EPR signal relative to these defects and the thermal decay of TL are in line with each other. Also, the activation energy of the paramagnetic centers and the trap depth obtained by kinetic analysis are nearly equal. Hence, the defects identified in EPR were responsible for TL in this glass. The electron trap was identified as oxygen vacancies, and the hole traps are the bridging oxygen atoms. When the glass is heated, the electrons are released from the electron trap and recombine with the trapped holes. From the obtained results, a mechanism for TL in these glasses is proposed.

\section{Ethics approval}

The manuscript has written as per journal ethical guidelines

\section{Consent to participate}

Yes, declare.

\section{Consent for publication}

Yes, declare.

\section{Availability of data, and materials}

Date will be shared, based on the request

\section{Funding}

The work has been completed, under Institute Internal research, and development scheme.

\section{Conflicts of Interest}

Declare None

\section{Authors contribution statement}

Dr. Ravi Kumar Guntu - conceptualization, methodology, characterization, analysis, report drafting and communication.

\section{Conflicts of Interest}

Declare None.

\section{Acknowledgements}

The author, Dr. RK Guntu, thank 
The Shri. K. Abijith Rao, CEO of Sreenidhi Educational Institutions, Hyderabad, Telangana State, INDIA, to provide Institute internal research grants to complete current investigation.

- Prof. C.V. Tomy, Director, Sreenidhi Institute of Science and Technology, JNT University, Hyderabad for providing valuable suggestions and guidelines.

- Dr. Ch. Srinivasa Rao, Andhra Loyola College, Krishna University, Vijayawada, Andhra Pradesh for providing valuable suggestions and guidelines.

- Prof. N. Ch. Srimannarayana Iyengar, Sreenidhi Institute of Science, and Technology, JNT University, Hyderabad for providing valuable suggestions and guidelines.

\section{Reference}

[1] Jia-Jun He, Shao-Yi Wu, Li-Juan Zhang, Yong-Qiang Xu, Chang-Chun Ding, Theoretical studies of the concentration dependences of $\mathrm{g}$ factor and d-d transition band for $\mathrm{Cr}^{3+}$ in $\mathrm{CdO}-\mathrm{SrO}-\mathrm{B}_{2} \mathrm{O}_{3}-\mathrm{SiO}_{2}$ glasses, Journal of Non-Crystalline Solids, Volume 437, 2016, Pages 58-63, ISSN 0022-3093, https://doi.org/10.1016/j.jnoncrysol.2016.01.019.

[2] M.S. Gaafar, S.Y. Marzouk, I.S. Mahmoud, Role of dysprosium on some acoustic and physical properties of $\mathrm{PbO}-\mathrm{B}_{2} \mathrm{O}_{3}-\mathrm{SiO}_{2}$ glasses, Results in Physics, Volume 22, 2021, 103944, ISSN 22113797, https://doi.org/10.1016/j.rinp.2021.103944.

[3] Fabien Pacaud, Mathieu Salanne, Thibault Charpentier, Laurent Cormier, Jean-Marc Delaye, Structural study of $\mathrm{Na}_{2} \mathrm{O}-\mathrm{B}_{2} \mathrm{O}_{3}-\mathrm{SiO}_{2}-\mathrm{La}_{2} \mathrm{O}_{3}$ glasses from molecular simulations using a polarizable force field, Journal of Non-Crystalline Solids, Volume 499, 2018, Pages 371-379, ISSN 0022-3093, https://doi.org/10.1016/j.jnoncrysol.2018.07.049.

[4] Byeongwon Park, Hong Li, L.René Corrales, Molecular dynamics simulation of $\mathrm{La}_{2} \mathrm{O}_{3}-\mathrm{Na}_{2} \mathrm{O}-\mathrm{SiO}_{2}$ glasses. I. The structural role of $\mathrm{La}^{3+}$ cations, Journal of Non-Crystalline Solids, Volume 297, Issues 2-3, 2002, Pages 220-238, ISSN 0022-3093, https://doi.org/10.1016/S0022-3093(01)00935-8.

[5] Hirokazu Masai, Go Okada, Noriaki Kawaguchi, Takayuki Yanagida, Photoluminescence and Xray-induced scintillation of $\mathrm{BaO}-\mathrm{TiO}_{2}-\mathrm{SiO}_{2}$ glasses and the glass-ceramics, Journal of NonCrystalline Solids, Volume 501, 2018, Pages 131-135, ISSN 0022-3093, https://doi.org/10.1016/j.jnoncrysol.2017.11.026.

[6] Maha Rai, Gavin Mountjoy, Molecular dynamics modelling of the structure of barium silicate glasses $\mathrm{BaO}-\mathrm{SiO}_{2}$, Journal of Non-Crystalline Solids, Volume 401, 2014, Pages 159-163, ISSN 0022-3093, https://doi.org/10.1016/j.jnoncrysol.2013.12.026.

[7] G. Ravi Kumar, M.C. Rao, Structural and photoluminescence investigations of $\mathrm{Cr}^{3+}$ mixed $\mathrm{Li}_{2} \mathrm{O}-$ $\mathrm{Bi}_{2} \mathrm{O}_{3}-\mathrm{ZrO}_{2}-\mathrm{SiO}_{2}$ glass ceramics for optoelectronic device application, Optik, Volume 181, 2019, Pages 721-731, ISSN 0030-4026, https://doi.org/10.1016/j.ijleo.2018.12.110.

[8] P. Goharian, B. Eftekhari Yekta, A.R. Aghaei, S. Banijamali, Lithium ion-conducting glass-ceramics in the system $\mathrm{Li}_{2} \mathrm{O}-\mathrm{TiO}_{2}-\mathrm{P}_{2} \mathrm{O}_{5}-\mathrm{Cr}_{2} \mathrm{O}_{3}-\mathrm{SiO}_{2}$, Journal of Non-Crystalline Solids, Volume 409, 2015, Pages 120-125, ISSN 0022-3093, https://doi.org/10.1016/j.jnoncrysol.2014.11.016.

[9] Taoyong Liu, Cui Li, Qianxing Huang, Chenxing Liu, Changwei Lin, Qian Zhang, Zhiwei Luo, Ligang Zhu, Anxian Lu, Characterization of structure and properties of $\mathrm{MgO}-\mathrm{Al}_{2} \mathrm{O}_{3}-\mathrm{SiO}_{2}-\mathrm{B}_{2} \mathrm{O}_{3}-$ 
$\mathrm{Cr}_{2} \mathrm{O}_{3}$ glass-ceramics, Journal of Non-Crystalline Solids, Volume 543, 2020, 120154, ISSN 00223093, https://doi.org/10.1016/j.jnoncrysol.2020.120154.

[10] Jau-Sheng Wang, Feng-Hsi Shen, The development of $\mathrm{SiO}_{2}$ resistant Cr-doped glass ceramics for high $\mathrm{Cr}^{3+}$ emission, Journal of Non-Crystalline Solids, Volume 358, Issue 2, 2012, Pages 246-251, ISSN 0022-3093, https://doi.org/10.1016/j.jnoncrysol.2011.09.022.

[11] B. Mirhadi, B. Mehdikhani, Crystallization behavior and microstructure of $\left(\mathrm{CaO} \cdot \mathrm{ZrO}_{2} \cdot \mathrm{SiO}_{2}\right)-\mathrm{Cr}_{2} \mathrm{O}_{3}$ based glasses, Journal of Non-Crystalline Solids, Volume 357, Issues 22-23, 2011, Pages 37113716, ISSN 0022-3093, https://doi.org/10.1016/j.jnoncrysol.2011.07.040.

[12] Ravi Kumar Guntu*, 'Elastic, thermoluminescence and dielectric characterization of lead antimony silicate glass composites doped by small concentrations of $\mathrm{Cr} 2 \mathrm{O} 3$ ', Bulletin Material Science, Volume 42, 2019, 214, ISSN 0250-4707, https://doi.org/10.1007/s12034-019-1892-3.

[13] Stelian Pintea, Vasile Rednic, Petru Mărginean, Nicolae Aldea, Hu Tiandou, Zhonghua Wu, Manfred Neumann, Florica Matei, Crystalline and electronic structure of Ni nanoclusters supported on $\mathrm{Al}_{2} \mathrm{O}_{3}$ and $\mathrm{Cr}_{2} \mathrm{O}_{3}$ investigated by XRD, XAS and XPS methods, Superlattices and Microstructures, Volume 46, Issues 1-2, 2009, Pages 130-136, ISSN 0749-6036, https://doi.org/10.1016/j.spmi.2009.01.003.

[14] G. Ravi Kumar, M. Gopi Krishna, M.C. Rao, $\mathrm{Cr}^{3+}$ doped $\mathrm{NaF}-\mathrm{ZrO}_{2}-\mathrm{B}_{2} \mathrm{O}_{3}-\mathrm{SiO}_{2}$ glass ceramic materials for optoelectronic device application, Optik, Volume 173, 2018, Pages 78-87, ISSN 00304026, https://doi.org/10.1016/j.ijleo.2018.07.114.

[15] T.Z. Todorova, D. Boyd, Thermal and elastic properties of binary and ternary high borate glass networks from first-principles methods, Journal of Non-Crystalline Solids, Volume 571, 2021, 121059, ISSN 0022-3093, https://doi.org/10.1016/j.jnoncrysol.2021.121059.

[16] Ravi Kumar Guntu, Ch. Srinivasa Rao, 'Influence of $\mathrm{Bi} 2 \mathrm{O} 3, \mathrm{Sb} 2 \mathrm{O} 3$ and $\mathrm{Y} 2 \mathrm{O} 3$ on optical properties of Er2O3-doped CaO-P2O5-B2O3 glasses', Bulletin Material Science, Volume 43, 2020, 71, ISSN 0250-4707, https://doi.org/10.1007/s12034-019-1996-9.

[17] Alaa M. Abd-Elnaiem, Gh. Abbady, A thermal analysis study of melt-quenched $\mathrm{Zn}_{5} \mathrm{Se}_{95}$ chalcogenide glass, Journal of Alloys and Compounds, Volume 818, 2020, 152880, ISSN 09258388, https://doi.org/10.1016/j.jallcom.2019.152880.

[18] Takashi Wakasugi, Takuya Kadoguchi, Rikuo Ota, Evaluation of the number density of nuclei in $\mathrm{Li}_{2} \mathrm{O} \cdot 2 \mathrm{SiO}_{2}$ glass by DTA method, Journal of Non-Crystalline Solids, Volume 290, Issue 1, 2001, Pages 64-72, ISSN 0022-3093, https://doi.org/10.1016/S0022-3093(01)00718-9.

[19] M.K. Halimah, C. Eevon, Comprehensive study on the effect of $\mathrm{Gd}_{2} \mathrm{O}_{3}$ NPs on elastic properties of zinc boro-tellurite glass system using non-destructive ultrasonic technique, Journal of NonCrystalline Solids, Volume 511, 2019, Pages 10-18, ISSN 0022-3093, https://doi.org/10.1016/j.jnoncrysol.2019.01.033.

[20] R. Hisam, A.K. Yahya, Elastic moduli, optical and electrical properties of mixed electronic-ionic $30 \mathrm{Li}_{2} \mathrm{O}-4 \mathrm{MoO}_{3}-(66-\mathrm{x}) \mathrm{TeO}_{2-\mathrm{x}} \mathrm{V}_{2} \mathrm{O}_{5}$ tellurite glass system, Results in Physics, Volume 13, 2019, 102219, ISSN 2211-3797, https://doi.org/10.1016/j.rinp.2019.102219.

[21] Vijay Singh, R.P.S. Chakradhar, J.L. Rao, S.H. Kim, EPR and luminescence studies of $\mathrm{Cr}^{3+}$ doped MgSrA110O17 phosphor synthesized by a low-temperature solution combustion route, Journal of Luminescence, Volume 154, 2014, Pages 328-333, ISSN 0022-2313, https://doi.org/10.1016/j.jlumin.2014.03.035. 
[22] A.R. Molla, C.R. Kesavulu, R.P.S. Chakradhar, A. Tarafder, S.K. Mohanty, J.L. Rao, B. Karmakar, S.K. Biswas, Microstructure, mechanical, thermal, EPR, and optical properties of $\mathrm{MgAl}_{2} \mathrm{O}_{4}: \mathrm{Cr}^{3+}$ spinel glass-ceramic nanocomposites, Journal of Alloys and Compounds, Volume 583, 2014, Pages 498-509, ISSN 0925-8388, https://doi.org/10.1016/j.jallcom.2013.08.122.

[23] F.S. De Vicente, F.A. Santos, B.S. Simões, S.T. Dias, M. Siu Li, EPR, optical absorption and luminescence studies of $\mathrm{Cr}^{3+}$-doped antimony phosphate glasses, Optical Materials, Volume 38, 2014, Pages 119-125, ISSN 0925-3467, https://doi.org/10.1016/j.optmat.2014.10.012.

[24] H.B. Premkumar, D.V. Sunitha, H. Nagabhushana, S.C. Sharma, B.M. Nagabhushana, J.L. Rao, Kinshuk Gupta, R.P.S. Chakradhar, $\mathrm{YAlO}_{3}: \mathrm{Cr}^{3+}$ nanophosphor: Synthesis, photoluminescence, EPR, dosimetric studies, Spectrochimica Acta Part A: Molecular and Biomolecular Spectroscopy, Volume 96, 2012, Pages 154-162,ISSN 1386-1425, https://doi.org/10.1016/j.saa.2012.04.028.

[25] G. Susoy, E.E. Altunsoy Guclu, Ozge Kilicoglu, M. Kamislioglu, M.S. Al-Buriahi, M.M. Abuzaid, H.O. Tekin, The impact of $\mathrm{Cr}_{2} \mathrm{O}_{3}$ additive on nuclear radiation shielding properties of $\mathrm{LiF}-\mathrm{SrO}-$ $\mathrm{B}_{2} \mathrm{O}_{3}$ glass system, Materials Chemistry and Physics, Volume 242, 2020, 122481, ISSN 0254-0584, https://doi.org/10.1016/j.matchemphys.2019.122481.

[26] M.S. Al-Buriahi, Y.S.M. Alajerami, A.S. Abouhaswa, Amani Alalawi, Tanin Nutaro, Baris Tonguc, Effect of chromium oxide on the physical, optical, and radiation shielding properties of lead sodium borate glasses, Journal of Non-Crystalline Solids, Volume 544, 2020, 120171, ISSN 0022-3093, https://doi.org/10.1016/j.jnoncrysol.2020.120171.

[27] M.I. Sayyed, H.O. Tekin, O. Agar, Gamma photon and neutron attenuation properties of MgO-BaO$\mathrm{B}_{2} \mathrm{O}_{3}-\mathrm{TeO}_{2}-\mathrm{Cr}_{2} \mathrm{O}_{3}$ glasses: The role of $\mathrm{TeO}_{2}$, Radiation Physics and Chemistry, Volume 163, 2019, Pages 58-66, ISSN 0969-806X, https://doi.org/10.1016/j.radphyschem.2019.05.012.

[28] M.S. Al-Buriahi, Y.S.M. Alajerami, A.S. Abouhaswa, Amani Alalawi, Tanin Nutaro, Baris Tonguc, Effect of chromium oxide on the physical, optical, and radiation shielding properties of lead sodium borate glasses, Journal of Non-Crystalline Solids,Volume 544, 2020, 120171, ISSN 0022-3093, https://doi.org/10.1016/j.jnoncrysol.2020.120171.

[29] Nimitha S. Prabhu, K. Sharmila, Swaroop Kumaraswamy, et.al., An examination of the radiationinduced defects and thermoluminescence characteristics of $\mathrm{Sm} 2 \mathrm{O} 3$ doped $\mathrm{BaO}-\mathrm{ZnO}-\mathrm{LiF}-\mathrm{B} 2 \mathrm{O} 3$ glass system for $\gamma$-dosimetry application, Optical Materials, Volume 118, 2021, 111252, ISSN 09253467,https://doi.org/10.1016/j.optmat.2021.111252.

[30] Nimitha S. Prabhu, Vinod Hegde, M.I. Sayyed, O. Agar, Sudha D. Kamath, Investigations on structural and radiation shielding properties of $\mathrm{Er}^{3+}$ doped zinc bismuth borate glasses, Materials Chemistry and Physics, Volume 230, 2019, Pages 267-276, ISSN 0254-0584,

https://doi.org/10.1016/j.matchemphys.2019.03.074.

[31] Ravi Kumar Guntu, $\mathrm{Nd}_{2} \mathrm{O}_{3}$ Influenced $\mathrm{Al}_{2} \mathrm{O}_{3} \& \mathrm{Sb}_{2} \mathrm{O}_{3}$ Functional PbO-SiO 2 Glass, Materials, $1.06 \mu \mathrm{m}$ Photonic Resource, Materials Science and Engineering: B, Volume 262, 2020, 114784, ISSN 0921-5107, https://doi.org/10.1016/j.mseb.2020.114784.

[32] R. Debnath, A.K. Chaudhuri, J.M. Luthra, S.G. Vaijapurkar, P.K. Bhatnagar,High temperature thermoluminescence of $\gamma$-irradiated copper activated silica glass and its application to dosimetry, Journal of Luminescence, Volume 65, Issue 5,1995, Pages 279-282, ISSN 0022-2313, https://doi.org/10.1016/0022-2313(95)00076-3.

[33] S.R. Anishia, M.T. Jose, O. Annalakshmi, V. Ponnusamy, V. Ramasamy, Dosimetric properties of rare earth doped $\mathrm{LiCaBO}_{3}$ thermoluminescence phosphors, Journal of Luminescence, Volume 130, Issue 10, 2010, Pages 1834-1840, https://doi.org/10.1016/j.jlumin.2010.04.019. 
[34] R. Laopaiboon, C. Bootjomchai, Physical properties and thermoluminescence of glasses designed for radiation dosimetry measurements, Materials \& Design,Volume 80, 2015, Pages 20-27, ISSN 02613069,https://doi.org/10.1016/j.matdes.2015.05.002.

[35] R. Debnath, A.K. Chaudhuri, J.M. Luthra, S.G. Vaijapurkar, P.K. Bhatnagar,High temperature thermoluminescence of $\gamma$-irradiated copper activated silica glass and its application to dosimetry, Journal of Luminescence, Volume 65, Issue 5, 1995, Pages 279-282, ISSN 0022-2313, https://doi.org/10.1016/0022-2313(95)00076-3.

[36] C.R. Kesavulu, R.S. Muralidhara, J.L. Rao, R.V. Anavekar, R.P.S. Chakradhar, EPR and photoluminescence studies on lithium-potassium borophosphate glasses doped with $\mathrm{Mn}^{2+}$ ions, Journal of Alloys and Compounds, Volume 486, Issues 1-2, 2009, Pages 46-50, https://doi.org/10.1016/j.jallcom.2009.07.040.

[37] Bhaskar Sanyal, M. Goswami, Shobha S, V. Prakasan, M. Krishnan, Sunil K. Ghosh, Thermoluminescence and electron paramagnetic resonance study on rare earth/transition metal doped lithium borate glasses for dosimetry applications, Journal of Luminescence, Volume 216, 2019, 116725, https://doi.org/10.1016/j.jlumin.2019.116725.

[38] Nilo F. Cano, T.K. Gundu Rao, Jorge S. Ayala-Arenas, Carlos D. Gonzales-Lorenzo, Letícia M. Oliveira, Shigueo Watanabe, TL in green tourmaline: Study of the centers responsible for the TL emission by EPR analysis, Journal of Luminescence, Volume 205, 2019, Pages 324-328, https://doi.org/10.1016/j.jlumin.2018.09.034.

[39] A.S. El-Bayoumi, Huda A. Alazab, F.M. Ezz-ElDin, The impact of $\gamma$-irradiation on $\mathrm{Cd}^{-\mathrm{B}_{2} \mathrm{O}_{3} \text { glass }}$ doped $\mathrm{WO}_{3}$ : New evidences by TL and ESR spectroscopy, Journal of Non-Crystalline Solids, Volume 551, 2021, 120459, https://doi.org/10.1016/j.jnoncrysol.2020.120459.

[40] A. Le Gac, B. Boizot, C. Jégou, S. Peuget, Aluminosilicate glasses structure under electron irradiation: An EPR study, Nuclear Instruments and Methods in Physics Research Section B: Beam Interactions with Materials and Atoms, Volume 407, 2017, Pages 203-209, https://doi.org/10.1016/j.nimb.2017.06.025. 


\section{Figures}
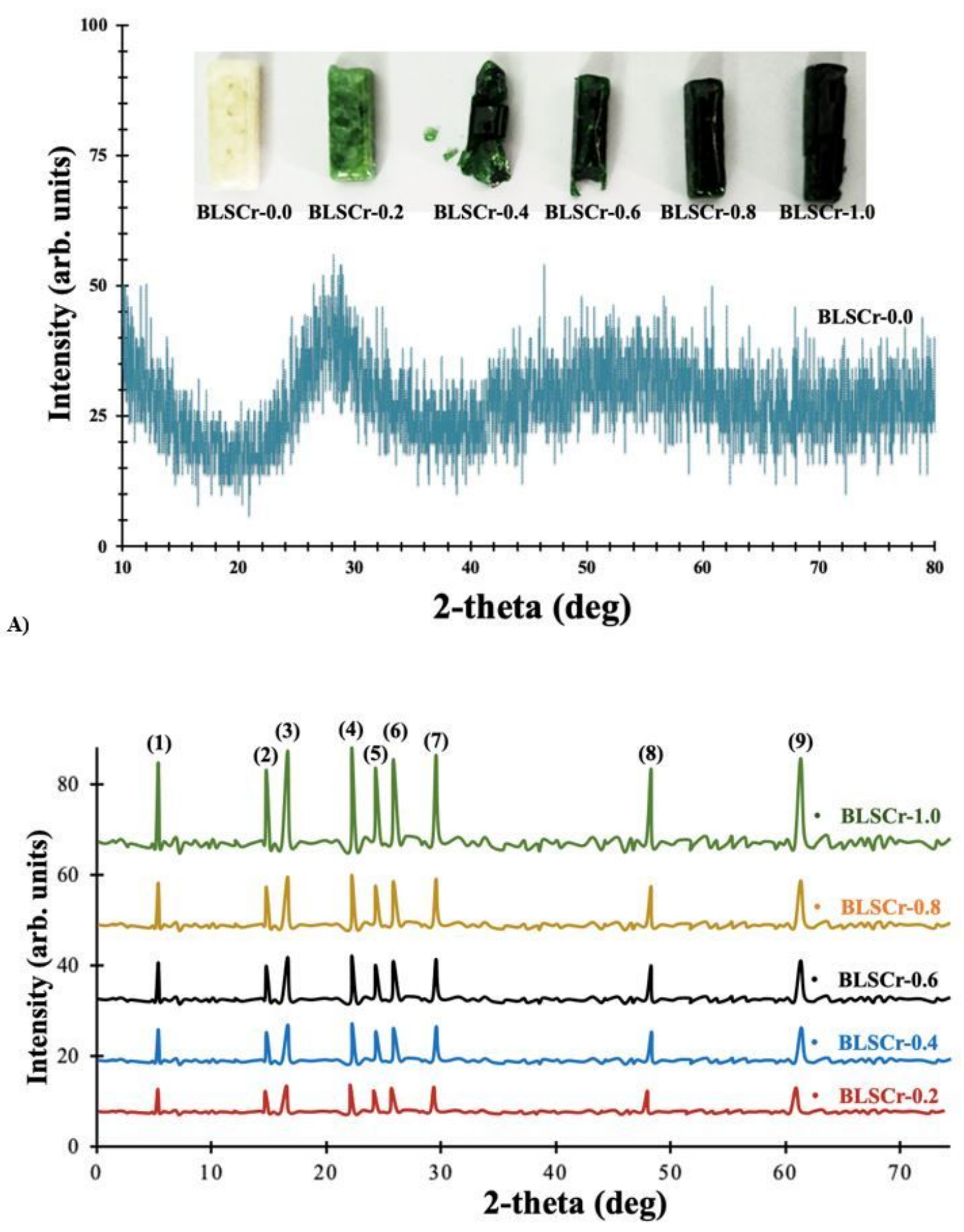

B)

Figure 1

(a) X-Ray diffraction pattern of the BLSCr-0.0 (24.0 BaO + 15 La2O3 + $60 \mathrm{SiO} 2+0.0 \mathrm{Cr} 2 \mathrm{O} 3)$ glass. Inset of the figure is the photograph of the $\mathrm{Ba}(25-\mathrm{x}) \mathrm{Crx}$ La15Si60 series of glasses. Where ' $\mathrm{x}$ ' varies 0 to $1 \mathrm{~mol} \%$ with a step size of $0.2 \mathrm{~mol} \%$ glass. The diffraction angles are taken up to an accuracy of \pm 0.10 . (b) X-Ray 
diffraction pattern of the $\mathrm{Ba}(25-\mathrm{x}) \mathrm{Crx}$ La15Si60 series of glasses. Where ' $\mathrm{x}$ ' varies 0 to $1 \mathrm{~mol} \%$ with a step size of $0.2 \mathrm{~mol} \%$. The diffraction angles are taken up to an accuracy of \pm 0.10 .

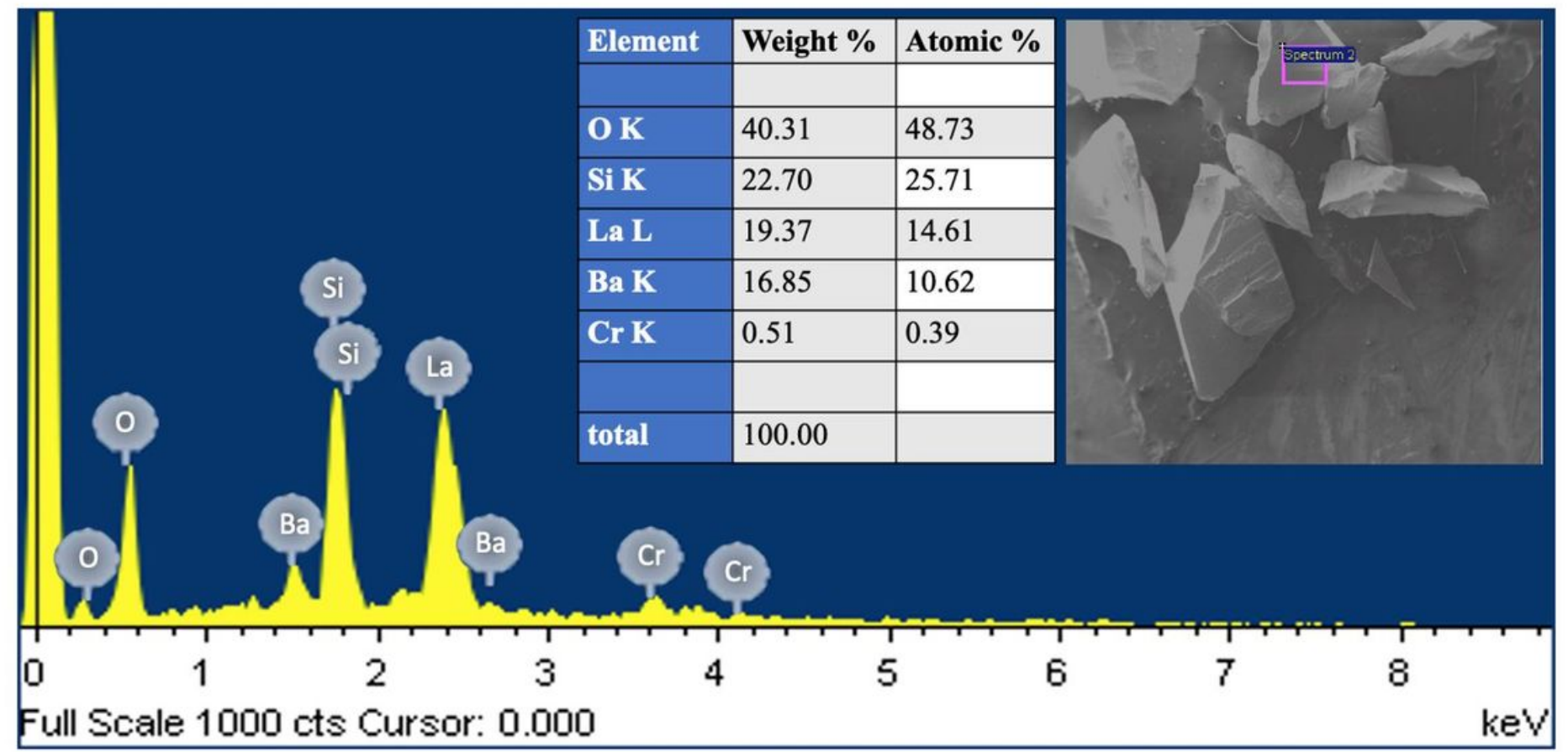

Figure 2

Chemical analysis of the BLSCr-1.0 glass is recorded at the room temperature. 


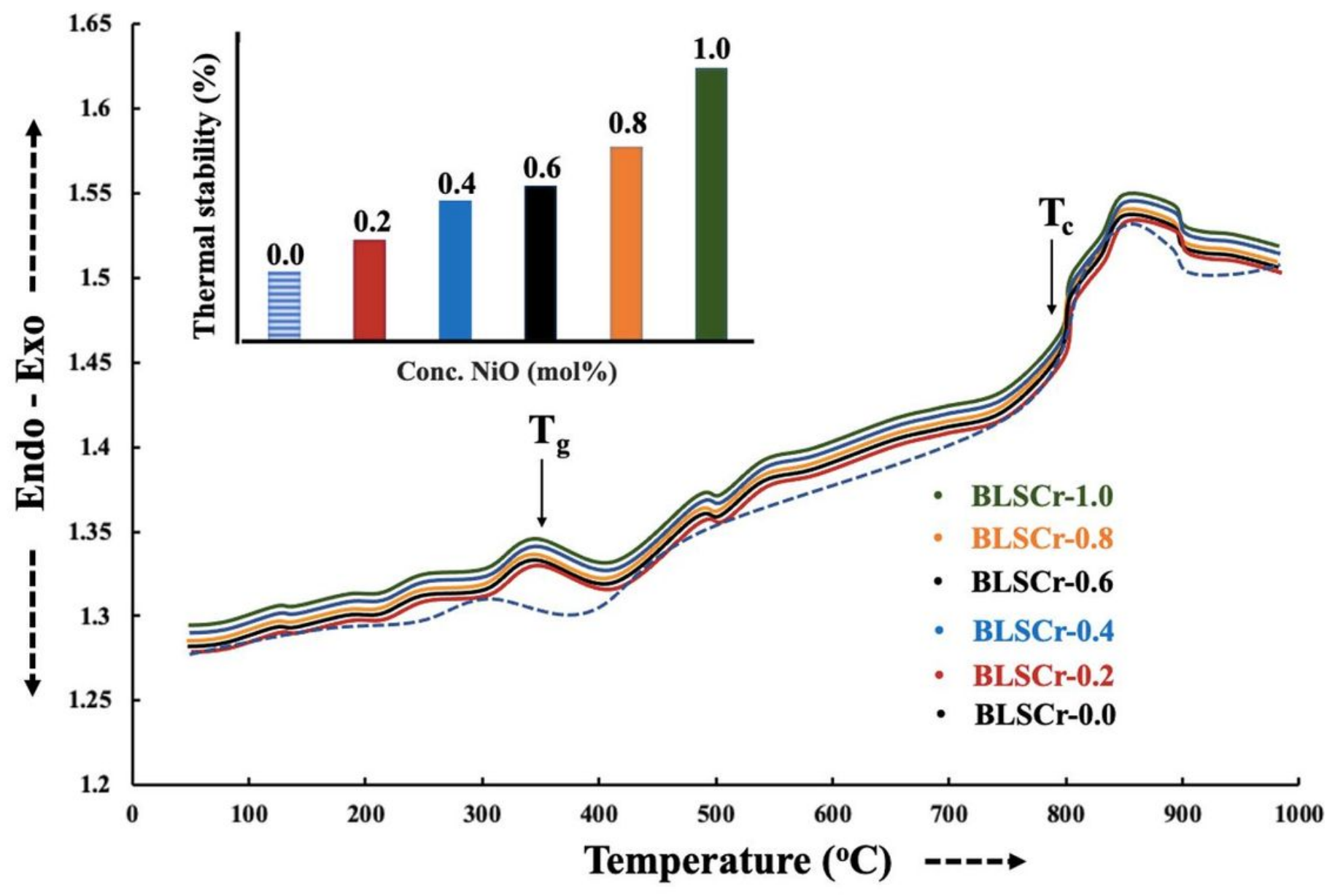

Figure 3

DTA thermograms of the $\mathrm{Ba}(25-\mathrm{x}) \mathrm{Crx}$ La15Si60 series of glasses, where ' $\mathrm{x}$ ' varies 0 to $1 \mathrm{~mol} \%$ with a step size of $0.2 \mathrm{~mol} \%$. The temperatures are taken up to an accuracy of $\pm 10 \mathrm{C}$. 


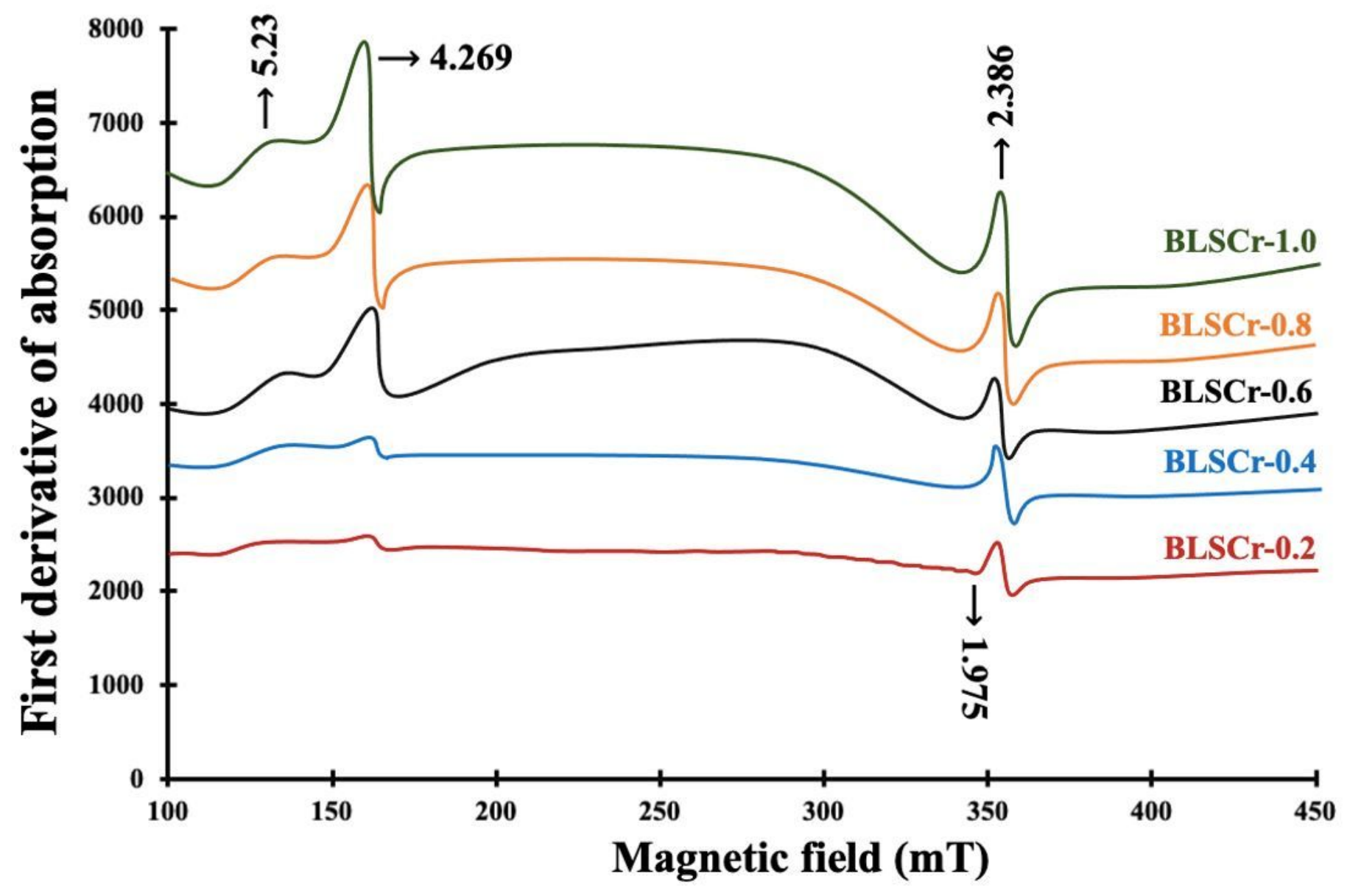

Figure 4

EPR Spectra of the $B a(25-x) C r x$ La15Si60 series of glasses, where ' $x$ ' varies 0 to 1 mol\% with a step size of $0.2 \mathrm{~mol} \%$. The magnetic field values are taken up to an accuracy of $\pm 0.1 \mathrm{mT}$. 

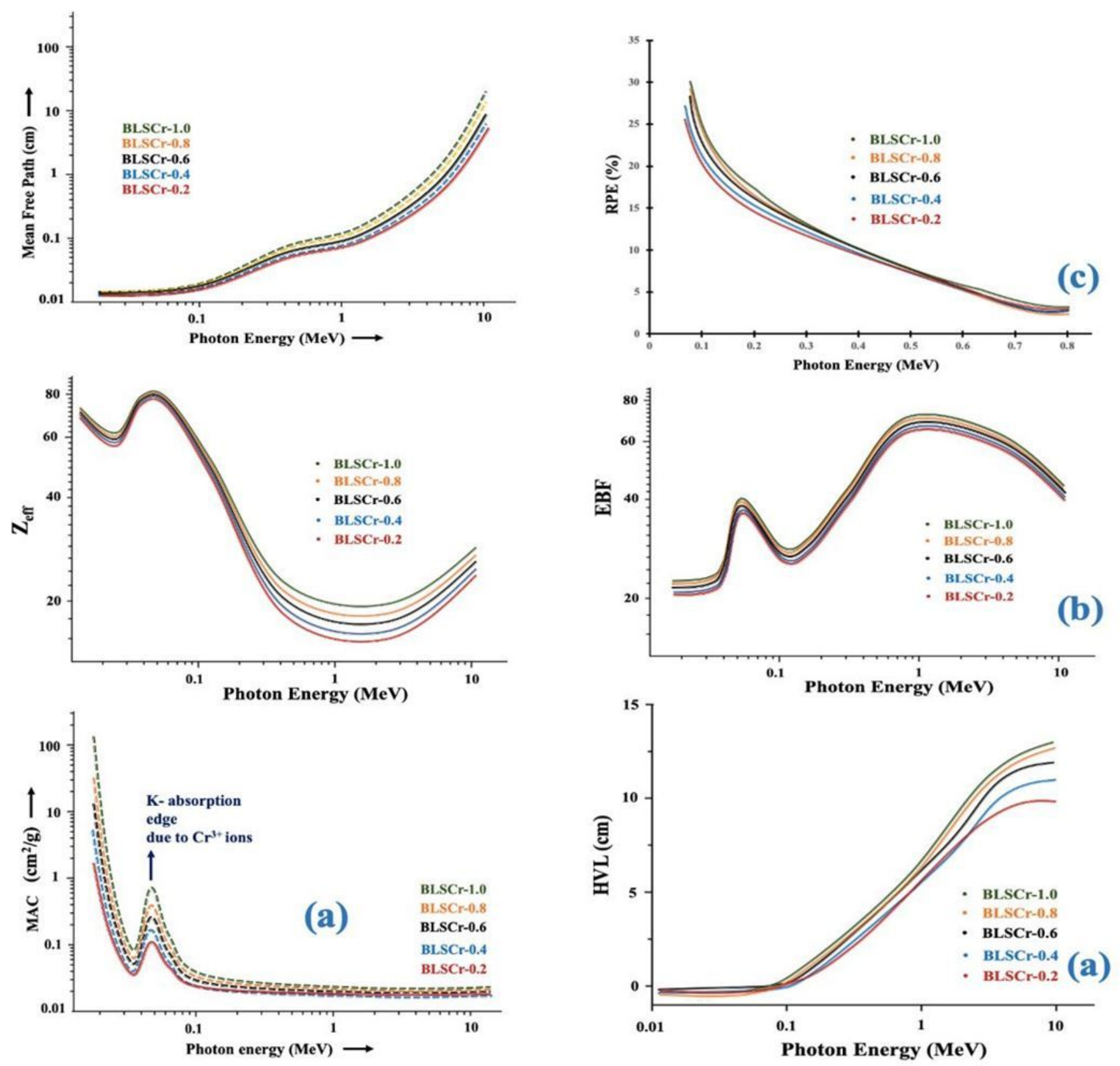

Figure 5

(a) Radiation shielding properties: variation in (a) effective atomic number, (b) mass attenuation coefficient and (c) mean free path with increasing photon energy and $\mathrm{Cr} 203$ concentration in $\mathrm{Ba}(25-\mathrm{x}) \mathrm{Crx}$ La15Si60 series of glasses, where ' $x$ ' varies 0 to $1 \mathrm{~mol} \%$ with a step size of $0.2 \mathrm{~mol} \%$. (b) Radiation shielding properties: variation in (a) half value layer, (b) energy build-up factor and (c) radiation protection efficiency with increasing photon energy and $\mathrm{Cr} 203$ concentration in $\mathrm{Ba}(25-\mathrm{x}) \mathrm{Crx}$ La15Si60 series of glasses, where ' $x$ ' varies 0 to $1 \mathrm{~mol} \%$ with a step size of $0.2 \mathrm{~mol} \%$. 


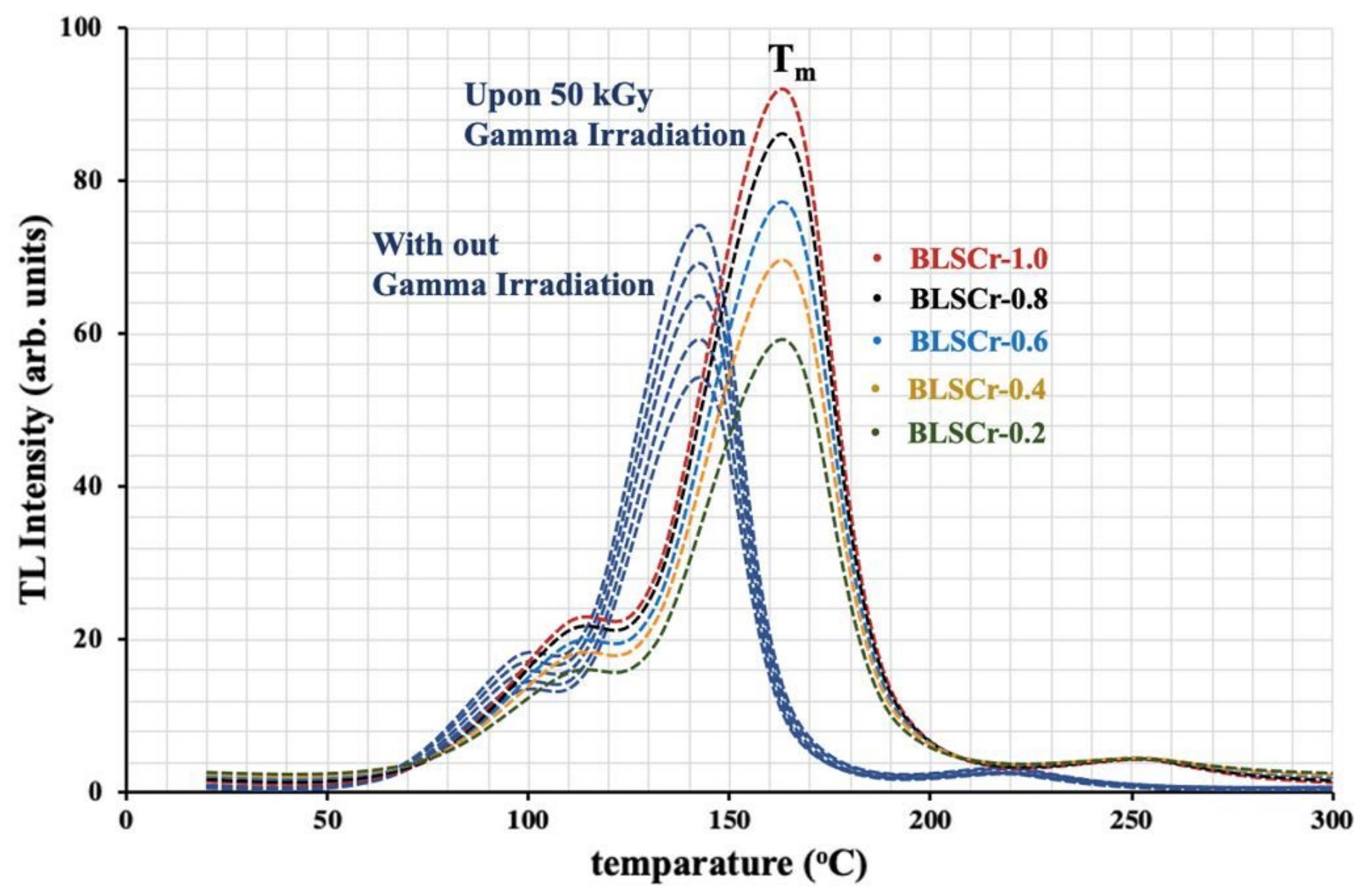

Figure 6

Thermoluminiscence analysis of the $\mathrm{Ba}(25-\mathrm{x}) \mathrm{Crx}$ La15Si60 series of glasses, where ' $\mathrm{x}$ ' varies 0 to $1 \mathrm{~mol} \%$ with a step size of $0.2 \mathrm{~mol} \%$. The temperatures are taken up to an accuracy of $\pm 0.1 \mathrm{oC}$. 


\section{After Irradiation}

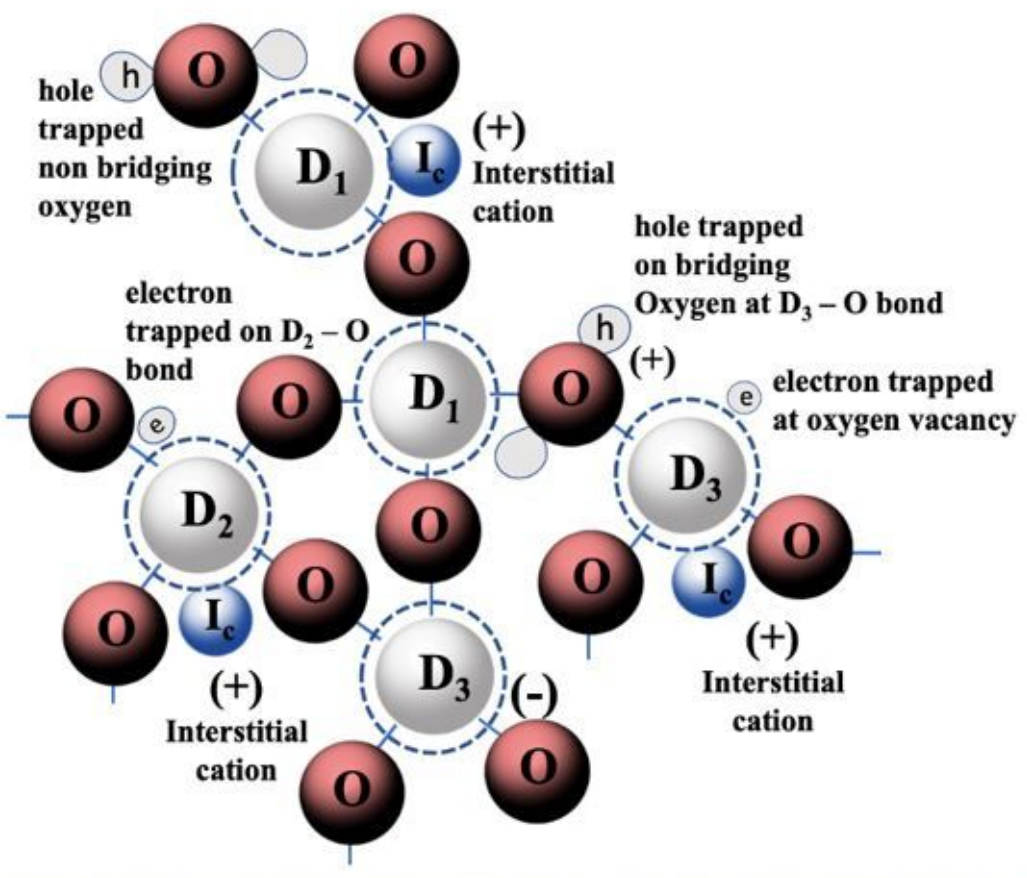

\section{Before Irradiation}

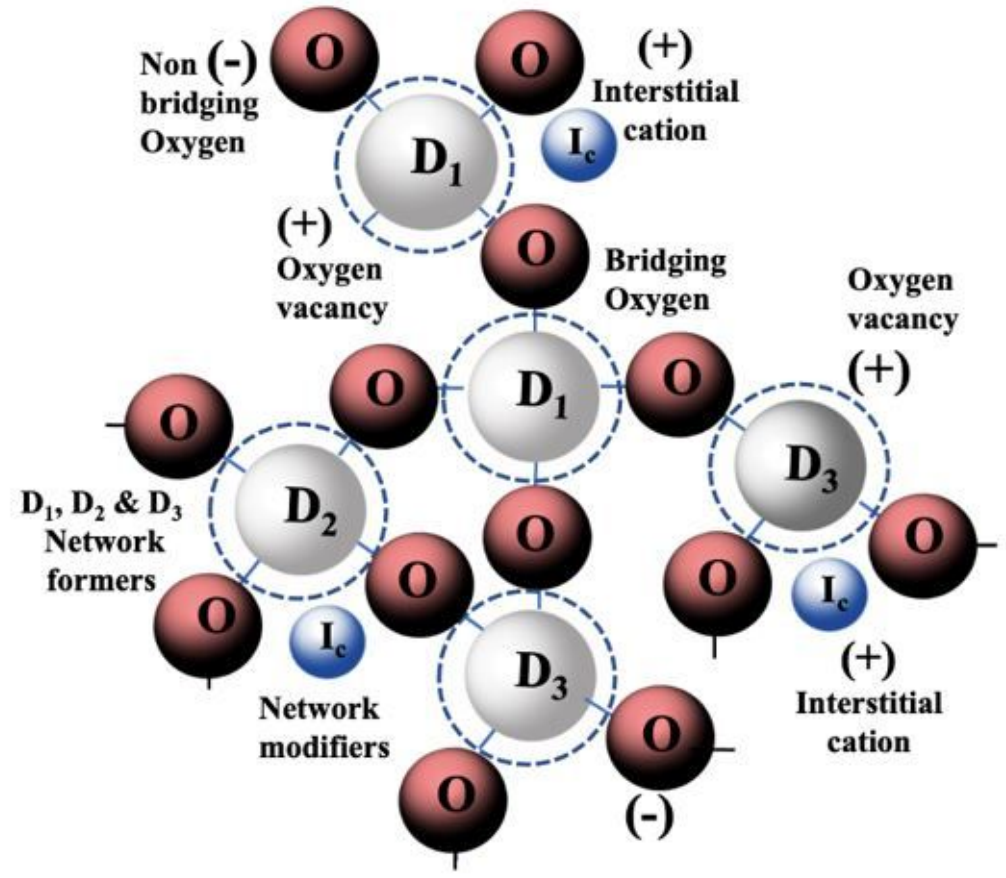

Figure 7

The schematic representation of the possible defect centers in the BLSCr-1.0 glass showing the different types of radiation induced paramagnetic centers and their relationship with pre-existing radiation defects in the lattice. Mac based Chem Draw Ultra version 12.0 was used to plot the figure. 

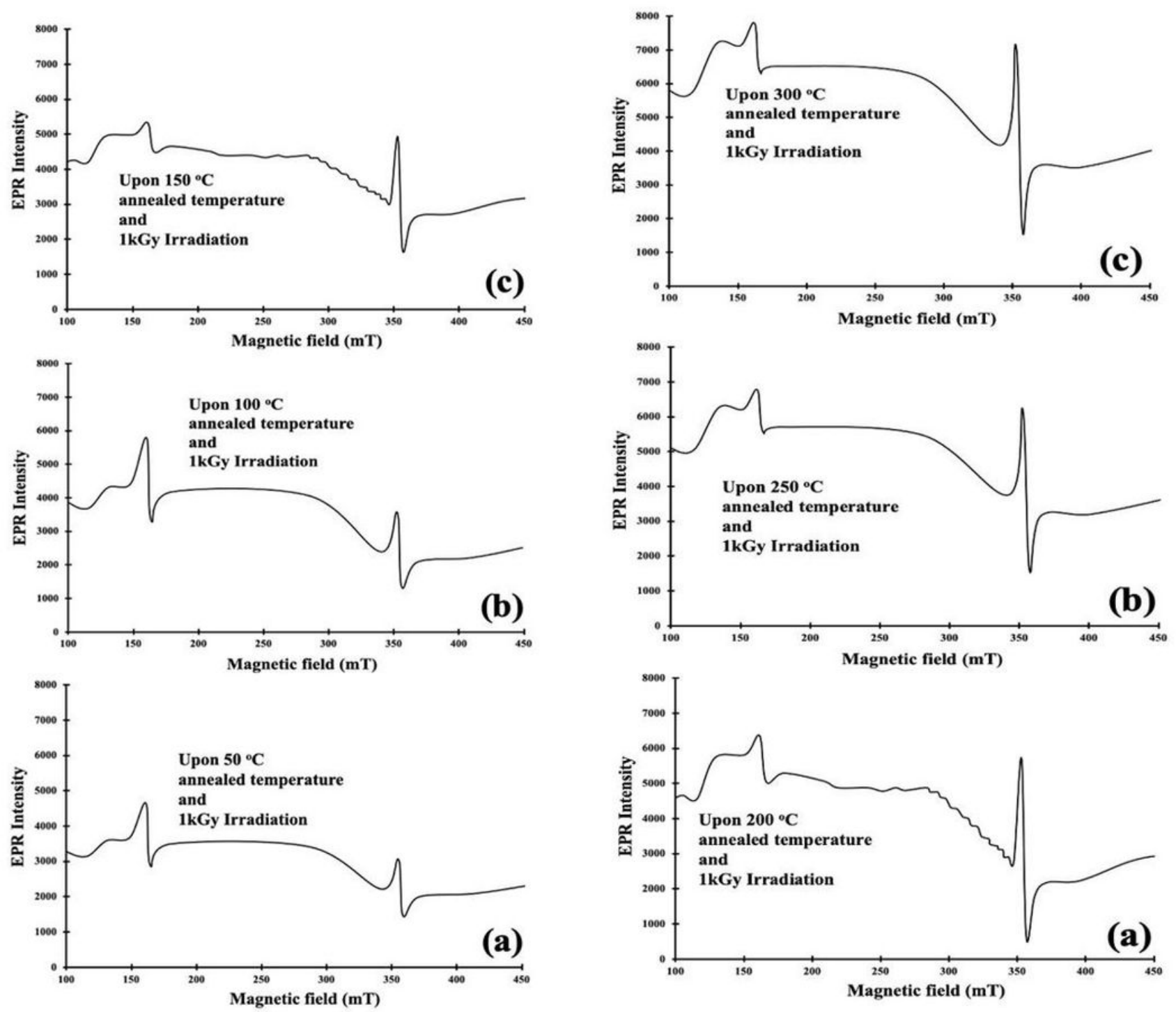

Figure 8

(a) The EPR spectrum (first derivative of absorption) of the BLSCr-1.0 glass under different conditions. The conditions are given in each of the plot. (b) The EPR spectrum (first derivative of absorption) of the BLSCr-1.0 glass is given in enlarged scale in order to isolate and identify the paramagnetic radicals formed upon irradiation. The conditions are given in each of the plot. 


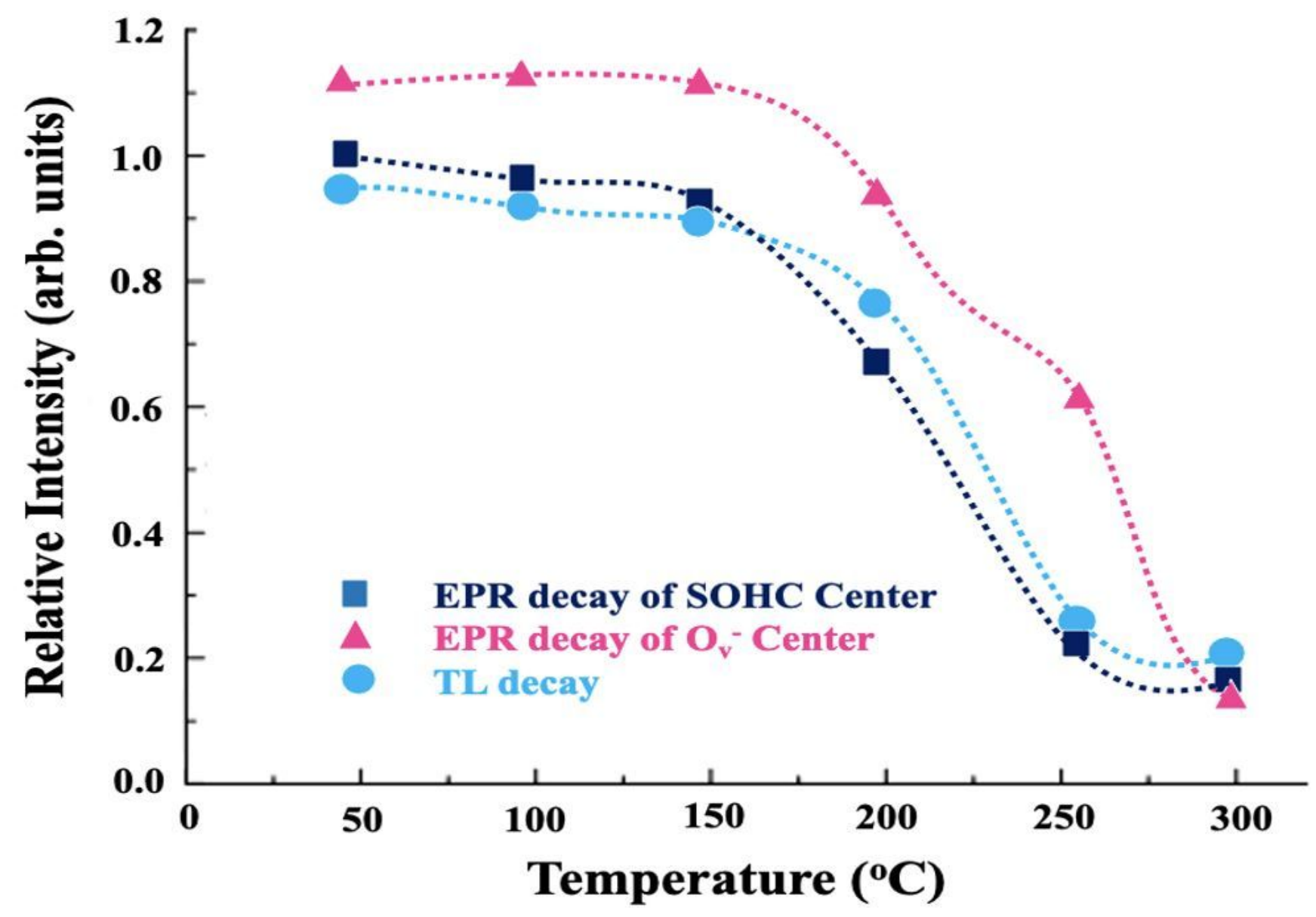

Figure 9

Upon irradiation, thermal decay of the TL and EPR signal of SOHC and oxygen vacancy O_囚) radicals formed with in the BLSCr-1.0 glass.

\section{Supplementary Files}

This is a list of supplementary files associated with this preprint. Click to download.

- Table1.jpg 